\title{
The role of roughage provision on the absorption and disposition of the mycotoxin deoxynivalenol and its acetylated derivatives in calves: from field observations to toxicokinetics
}

\author{
Bonnie Valgaeren ${ }^{1,2}$. Léonard Théron ${ }^{3} \cdot$ Siska Croubels $^{4} \cdot$ Mathias Devreese $^{4}$. Siegrid De Baere ${ }^{4}$ \\ Els Van Pamel ${ }^{5}$. Els Daeseleire ${ }^{5}$. Marthe De Boevre ${ }^{6}$. Sarah De Saeger ${ }^{6} \cdot$ Arnau Vidal $^{6}$. José Diana Di Mavungu ${ }^{6}$. \\ Philipp Fruhmann $^{7,8} \cdot$ Gerhard Adam $^{8}$. Alfons Callebaut ${ }^{9} \cdot$ Calixte Bayrou $^{10} \cdot$ Vincent Frisée $^{3}$. Anne-Sophie Rao ${ }^{3}$. \\ Emilie Knapp $^{3} \cdot$ Arnaud Sartelet $^{3} \cdot$ Bart Pardon $^{1} \cdot$ Piet Deprez $^{1} \cdot$ Gunther Antonissen ${ }^{4,11}$ (]
}

Received: 28 March 2018 / Accepted: 29 November 2018

(c) Springer-Verlag GmbH Germany, part of Springer Nature 2018

\begin{abstract}
A clinical case in Belgium demonstrated that feeding a feed concentrate containing considerable levels of deoxynivalenol (DON, $1.13 \mathrm{mg} / \mathrm{kg}$ feed) induced severe liver failure in 2- to 3-month-old beef calves. Symptoms disappeared by replacing the highly contaminated corn and by stimulating ruminal development via roughage administration. A multi-mycotoxin contamination was demonstrated in feed samples collected at 15 different veal farms in Belgium. DON was most prevalent, contaminating $80 \%$ of the roughage samples (mixed straw and maize silage; average concentration in positives: $637 \pm 621 \mu \mathrm{g}$ / $\mathrm{kg}$, max. $1818 \mu \mathrm{g} / \mathrm{kg}$ ), and all feed concentrate samples $(411 \pm 156 \mu \mathrm{g} / \mathrm{kg}$, max. $693 \mu \mathrm{g} / \mathrm{kg})$. In order to evaluate the impact of roughage provision and its associated ruminal development on the gastro-intestinal absorption and biodegradation of DON and its acetylated derivatives (3- and 15-ADON) in calves, a toxicokinetic study was performed with two ruminating and two non-ruminating male calves. Animals received in succession a bolus of DON (120 $\mu \mathrm{g} / \mathrm{kg}$ bodyweight (BW)), 15-ADON $(50 \mu \mathrm{g} / \mathrm{kg} \mathrm{BW})$, and 3-ADON $(25 \mu \mathrm{g} / \mathrm{kg})$ by intravenous (IV) injection or per os (PO) in a cross-over design. The absolute oral bioavailability of DON was much higher in non-ruminating calves $(50.7 \pm 33.0 \%)$ compared to ruminating calves $(4.1 \pm 4.5 \%)$. Immediately following exposure, 3 - and 15-ADON were hydrolysed to DON in ruminating calves. DON and its acetylated metabolites were mainly metabolized to DON-3-glucuronide, however, also small amounts of DON15-glucuronide were detected in urine. DON degradation to deepoxy-DON (DOM-1) was only observed to a relevant extent in ruminating calves. Consequently, toxicity of DON in calves is closely related to roughage provision and the associated stage of ruminal development.
\end{abstract}

Keywords Biodegradation $\cdot$ Calf $\cdot$ Deoxynivalenol $\cdot 3$ - and 15-Acetyldeoxynivalenol $\cdot$ Mycotoxin $\cdot$ Toxicokinetics

Bonnie Valgaeren and Léonard Théron contributed equally to this work.

Alfons Callebaut: Deceased.

Electronic supplementary material The online version of this article (https://doi.org/10.1007/s00204-018-2368-8) contains supplementary material, which is available to authorized users.

Gunther Antonissen

Gunther.Antonissen@UGent.be

Extended author information available on the last page of the article

\section{Introduction}

Mycotoxins are toxic secondary metabolites, produced by different fungal species, predominantly of the genera Aspergillus, Penicillium and Fusarium. In the temperate climate of Western Europe, Fusarium is one of the most important toxigenic fungal genera infecting different cereal crops (Schatzmayr and Streit 2013). Although members of this genus can cause grain yield losses, the interest in Fusarium head blight is primarily fuelled by the ability of the majority of the Fusarium species to produce mycotoxins. These mycotoxins exhibit toxicity and pose a potential acute or chronic health threat to humans and animals upon ingestion of contaminated food or feed (Antonissen et al. 2014, 2015; 
Bennett and Klich 2003). The mycotoxin deoxynivalenol (DON) is one of the most frequently detected Fusarium mycotoxins in feed and feed raw materials (Kovalsky et al. 2016). DON is a type B trichothecene mainly produced by F. graminearum and F. culmorum (Bottalico 1998). It is well known that DON acts as an inhibitor of the protein synthesis at the ribosomal level (Thompson and Wannemacher 1986). Therefore, it is suggested that rapidly proliferating cells and tissues with high protein turnover rates, such as the immune system, liver, and gastrointestinal tract are most affected (Maresca 2013; Pestka and Smolinski 2005). Hence, this can lead to poor production results in farm animals and an enhanced susceptibility to infectious diseases (Antonissen et al. 2014).

In addition to the free mycotoxin DON, other forms that are plant derived, such as deoxynivalenol-3- $\beta$-D-glucoside (DON3G), or fungus-derived, such as 3-acetyldeoxynivalenol (3-ADON), and 15-acetyldeoxynivalenol (15-ADON), are frequently detected in food and feed as well (Berthiller et al. 2013; Broekaert et al. 2015a; De Boevre et al. 2012; Van Asselt et al. 2012). In pigs, both ADONs are completely absorbed following oral administration, while the oral bioavailability of DON and acetylated derivatives is rather low in broiler chickens (Broekaert et al. 2015b). For DON, it has been demonstrated multiple factors might influence the oral bioavailability of DON such as the prandial state (fed versus fasted), the administration of a bolus versus the administration of contaminated feed, feed composition, and breed (Broekaert et al. 2015b; Eriksen and Pettersson 2004; Goyarts and Dänicke 2006; Prelusky et al. 1988; Saint-Cyr et al. 2015). Taking into account the substantial to complete presystemic hydrolysis of both ADONs, in broiler chickens and pigs, these acetylated forms can be regarded as potent as DON itself with regard to systemic toxicity (Broekaert et al. 2015b). The same has been reported for DON3G in pigs where a complete presystemic hydrolysis takes place (Broekaert et al. 2017). Furthermore, DON and its acetylated forms are metabolized to DON-glucuronides (GlcA) or DON-sulfate, which are both phase II metabolites (Payros et al. 2016; Schwartz-Zimmermann et al. 2015). Glucuronidation of DON has been identified as a major biotransformation pathway in mammals (Maul et al. 2012). In contrast, DON-3-GlcA is only a minor phase II metabolite in broilers and turkey poults. It has been demonstrated that poultry biotransform DON more extensively to the sulfate conjugate, such as DON-3 $\alpha$-sulfate, pointing towards species-specific metabolism (Devreese et al. 2015; Wan et al. 2014). Besides, sulfonation has been described for rats, however, its mechanism had not yet been elucidated (Schwartz-Zimmermann et al. 2014; Wan et al. 2014).

In general, the susceptibility of ruminants to DON is suggested to be low, as DON is converted into the less toxic de-epoxy-deoxynivalenol (DOM-1) by the ruminal flora
(Fink-Gremmels 2008). Studies by Ingalls (1996) and Yoshizawa et al. (1986) showed that ruminating cattle might tolerate diets containing up to $14.6 \mathrm{mg} \mathrm{DON} / \mathrm{kg}$ feed for 3 weeks without major health effects. However, Dänicke et al. (2005) reported a transiently increased post-prandial ammonia concentration in the rumen and a reduction in duodenal flow of microbial protein when feeding cows a wheat-based diet contaminated with DON, at concentrations of $3.1-3.5 \mathrm{mg}$ $\mathrm{DON} / \mathrm{kg}$ of daily diet at a reference dry matter (DM) content of $88 \%$. Consequently, the impact of DON ingestion in ruminants is still controversial and needs further clarification. Fink-Gremmels (2008) suggested that there is a correlation between the ruminal capacity to inactivate certain mycotoxins, and the likelihood of adverse health effects in cattle. A diet that provides sufficient amounts of roughage is required to maintain a functional ruminal flora. On the other hand, intensive feeding regimes, which are used in the specialized modern veal and beef industry in order to maximize production efficiency, include an increased feed concentrate provision (containing grains such as wheat, barley and corn). In the beef industry, rations are very variable. Some farms are known to feed a ration with a low roughage to feed concentrate ratio in order to maximize energy intake and growth, leading to a delay of ruminal development and fermentation (Zhang et al. 2018). In contrast, the veal industry is highly integrated, and the diet is similar for all farms. The calves are predominantly fed with milk replacer, complemented with a minimum of $250 \mathrm{~g}$ to $2 \mathrm{~kg}$ per day per calf of a mixture of $90 \%$ whole grains, mixed with $10 \%$ chopped straw. This roughage to feed concentrate ratio is insufficient to induce normal rumination and ruminal fermentation (Berends et al. 2014; Webb et al. 2015).

The European Food Safety Authority (EFSA) panel on contaminants in the food chain (CONTAM) noted that the risk for DON and its acetylated metabolites could be higher for pre-ruminant animals such as calves (Knutsen et al. 2017). Accordingly, the European Union maximum guidance levels of DON in complete feed for young calves ( $<4$ months of age) are lower compared to adult ruminants, 2 versus $5 \mathrm{mg}$ DON/kg feed, respectively (2006/576/EC). However, current legislation does not take into account acetylated forms of DON and the variation in ruminal development between different ruminant production systems such as dairy, beef and veal into account.

Furthermore, data from monogastric animals showed that also mycotoxin contamination levels below these European guidance levels can compromise several intestinal functions, such as digestion, absorption, permeability, and susceptibility to intestinal and systemic infectious diseases, which can result in lower productivity and poor health of animals (Antonissen et al. 2014, 2015; Bouhet and Oswald 2005; Gallo et al. 2015; Pinton and Oswald 2014). Besides gastrointestinal toxicity, DON-induced hepatotoxicity was reported 
in piglets fed a DON-contaminated diet (1.5-2.8 mg/kg feed) for 4-5 weeks (Bracarense et al. 2012; Gerez et al. 2015). Also, in in vitro studies with porcine and human hepatocytes exposed to different doses of DON $(0.1-100 \mu \mathrm{g} / \mathrm{mL})$, p38 activation initiated the apoptotic response resulting in caspase-3 activation (Königs et al. 2008; Mikami et al. 2004).

The negative impact of Fusarium contaminated diets at levels below the EU guidance levels was also observed in young calves during a clinical case at our department [Clinic for Ruminants of the University of Liège (Belgium)] and could be attributed to a non-optimal ruminal development caused by a shortage of roughage. This clinical case, which is described in detail in the next paragraph, together with the fact that studies investigating the role of ruminal development in the absorption and biodegradation of DON and its acetylated forms in calves are lacking, formed the basis for the current study. Therefore, the aims of this study were (1) to determine the occurrence of mycotoxins in veal feed components, (2) and to assess the toxicokinetic characteristics and absolute oral bioavailability of DON and its acetylated derivatives (3-ADON and 15-ADON) in ruminating and non-ruminating calves. In addition to DOM-1, major phase II metabolites were studied.

\section{Clinical case report}

In January 2015, a large commercial beef crossbred Belgian Blue farm (500 calvings/year, births non-seasonalized, bovine viral diarrhea-free status) submitted a case of fatal icterus in a 2-month-old calf (calf 1 ) to the Clinic for Ruminants of the University of Liège (Belgium) for necropsy. Prior to this case, on the same farm one calf with severe icterus died, however, no further examinations were performed. In the past, a case of icterus due to a Salmonella Dublin hepatocholecystitis had also been diagnosed on this farm (Ronzoni et al. 2013). Gross pathology revealed generalized icterus, mild bilirubinuria, splenomegaly, and no macroscopic lesions to the liver. Subsequently, a few weeks later another 2-month-old calf (calf 2) was referred to the clinic. On clinical examination the animal was lethargic, and had a normal body temperature, generalized icterus, and mild diarrhea. Blood analysis showed severe anemia, leukocytosis, bilirubinemia, and increased levels of aspartate aminotransferase (AST), and gamma-glutamyl transferase (GGT) (Supplementary Table 1). The blood lead and copper levels were within the normal range, and the calf tested negative for leptospirosis by serology. The animal was hospitalized and treated symptomatically with fluid therapy $[0.9 \% \mathrm{NaCl}$ intravenously $(2 \mathrm{~mL} / \mathrm{kg} / \mathrm{h})]$ and choleretics (Hepalac ${ }^{\mathrm{TM}}$, Savetis, Quevert, France). During hospitalization the animal was fed milk replacer (10\% of BW in 5 meals per day) and commercial calf feed concentrate.
After 4 days the calf recovered and was discharged from the clinic. Finally, a third calf (calf 3) was referred to the clinic. The animal was in poor clinical condition, with a more pronounced chronic liver failure characterized by very high glutamate dehydrogenase (GLDH) blood levels, but no anemia (Supplementary Table 1). Despite supportive symptomatic treatment the animal died within a few hours following submission to the clinic. Necropsy showed petechia and hemorrhages in the abomasum, congestive mucosae in the distal bowel, white debris in the kidney medulla, dark urine and splenomegaly. Bile bacteriology and leptospirosis PCR on urine was negative. Histopathological examination of the liver revealed a severe degeneration associated with a disruption of the parenchyma, fibrosis, biliary hyperplasia, cholestasis, steatosis, and infiltration of lymphocytes and macrophages, compatible with chronic metabolic disorder (Fig. 1).

Taking into account the fact that only 2- to 3-month-old calves were affected, a nutritional etiology was suspected. On the farm, calves were housed individually and fed milk replacer and commercial calf starter feed concentrate until 1 month of age. No calves with icterus were observed in this age category. Between 1 and 3 months of age, the animals were group-housed, and fed milk replacer and a farm-made feed concentrate, composed of cornmeal, barley flakes, wheat bran pellet, dehydrated beet pulp, tanned soybeans, de-hulled spelt, cacao pods, molasses, minerals, vitamins and trace elements. At farm level four out of 150 calves showed icterus. Animals older than 3 months were grouphoused and fed the same farm-made feed concentrate, but no milk replacer, and showed no symptoms. Subsequently, the presence of mycotoxins in the feed was analyzed by a validated multi-mycotoxin liquid chromatography-tandem mass

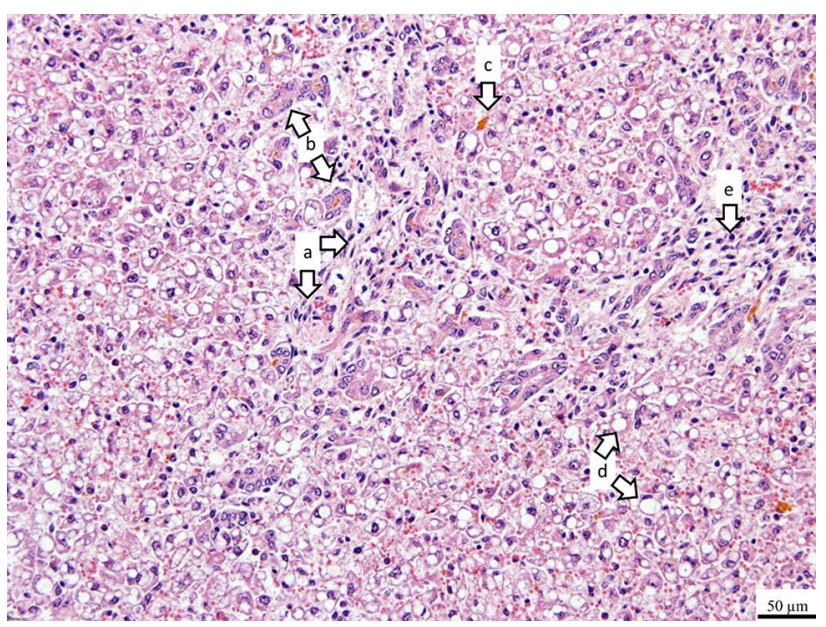

Fig. 1 Liver histopathology of calf no. 3 (hematoxylin and eosin staining) showing severe degeneration associated with a disruption of the parenchyma, fibrosis (a), biliary hyperplasia (b), cholestasis (c), steatosis (d), and infiltration of lymphocytes and macrophages (e) 
spectrometry method (LC-MS/MS) at the national reference laboratory for mycotoxins (CODA-CERVA, Tervuren, Belgium). The different feed commodities were analyzed for the presence of the following mycotoxins: aflatoxin $B_{1}$ $\left(\mathrm{AFB}_{1}\right), \mathrm{B}_{2}\left(\mathrm{AFB}_{2}\right), \mathrm{G}_{1}\left(\mathrm{AFG}_{1}\right), \mathrm{G}_{2}\left(\mathrm{AFG}_{2}\right)$ and $\mathrm{M}_{1}\left(\mathrm{AFM}_{1}\right)$ (only in milk replacer sample), DON, 3-ADON, 15-ADON, fumonisin $\mathrm{B}_{1}\left(\mathrm{FB}_{1}\right), \mathrm{B}_{2}\left(\mathrm{FB}_{2}\right)$ and $\mathrm{B}_{3}\left(\mathrm{FB}_{3}\right)$, ochratoxin $\mathrm{A}$ (OTA), T-2 toxin (T-2), HT-2 toxin (HT-2) and ZEN. The cornmeal was highly contaminated with several Fusarium mycotoxins, i.e., $4.27 \mathrm{mg}$ DON, $1.40 \mathrm{mg} 15-\mathrm{ADON}, 0.05 \mathrm{mg}$ 3 -ADON and $0.42 \mathrm{mg}$ ZEN per kg. Furthermore, DON was also found in soybeans $(0.68 \mathrm{mg} / \mathrm{kg})$, wheat bran $(0.37 \mathrm{mg} /$ $\mathrm{kg})$, and spelt $(0.23 \mathrm{mg} / \mathrm{kg})$. Besides, $15-\mathrm{ADON}$ was also detected in the soybeans $(0.15 \mathrm{mg} / \mathrm{kg})$ and a low level of $\mathrm{T}-2(0.02 \mathrm{mg} / \mathrm{kg})$ was found in the spelt. The cacao pods were contaminated with $15-\mathrm{ADON}(0.22 \mathrm{mg} / \mathrm{kg})$ and OTA $(0.004 \mathrm{mg} / \mathrm{kg})$. The final mycotoxin level in the total farmmade feed concentrate was $1.13 \mathrm{mg}$ DON and $0.15 \mathrm{mg}$ ZEN per $\mathrm{kg}$. No mycotoxins were detected in the milk replacer. Consequently, the mycotoxin concentration of the administered diet did not exceed the EU maximum guidance levels for DON (2 mg/kg) and ZEN (0.5 mg/kg) (2006/576/ EC), although, clear clinical symptoms of liver failure were observed in calves fed this diet and other causes of liver failure, such as salmonellosis, leptospirosis, and lead and copper intoxication, were excluded. Therefore, to demonstrate the possible role of mycotoxins, blood values of liver enzymes and liver function markers were assessed prior and after a diet change. Blood samples were withdrawn from six different calves of 2- to 3-month-old of two different pens, and different liver enzymes and liver function markers were analyzed (Table 1). Subsequently, the diet of these animals was changed to a new diet. To stimulate ruminal development roughage, more specifically hay, was introduced into the diet. Besides, the source of corn was changed, since the

Table 1 Blood concentrations of liver enzymes and liver function markers in six 2- to 3-month-old calves fed a Fusarium mycotoxincontaminated diet (original diet, $1.13 \mathrm{mg}$ DON and $0.15 \mathrm{mg}$ ZEN per $\mathrm{kg}$ feed) and 2 weeks after the diet was changed to a new source of corn and the introduction of hay (new diet)

\begin{tabular}{lllcl}
\hline & Original diet & New diet & Reference value $^{\mathrm{a}}$ & $P$ value \\
\hline AST (U/L) & $173 \pm 141$ & $76 \pm 18$ & $78-132$ & 0.127 \\
GLDH (U/L) & $148 \pm 90$ & $58 \pm 54$ & $0-60$ & 0.060 \\
GGT (U/L) & $112 \pm 68$ & $44 \pm 21$ & $6-17$ & $0.040^{*}$ \\
TBA (mg/L) & $270 \pm 345$ & $49 \pm 22$ & $0.1-5$ & 0.147 \\
\hline
\end{tabular}

Values are presented as means $\pm \mathrm{SD}$

$A S T$ aspartate aminotransferase, $G L D H$ glutamate dehydrogenase, $G G T$ gamma-glutamyl transferase, $T B A$ total bile acids

*Significantly different between calves fed the original diet compared to animals fed the new diet

${ }^{\text {a S}}$ Smith and Magdesian (2009) original cornmeal made one quarter of the farm-made feed concentrate and was highly contaminated with Fusarium mycotoxins. After 2 weeks, blood levels of liver enzymes and function markers were analyzed again in the same six calves (Table 1). Blood values of liver enzymes and liver function markers differed statistically compared prior and after dietary change, as demonstrated by a paired $t$ test (SPSS 24.0, Chicago, IL, USA). A significant decrease was observed for GGT $(P=0.040)$.

\section{Materials and methods}

\section{Occurrence of mycotoxins in veal feed components}

\section{Sample collection}

On 15 Flemish veal farms (5 farms specialized in raising Holstein Friesian veal calves, 5 in raising Belgian Blue veal calves and 5 in raising crossbred calves), a total of 45 feed samples were collected. On each farm, samples of the milk replacer, roughage source and feed concentrate were collected. The sampled milk replacers, so-called nill product, were composed of a variable percentage of whey powder supplemented with vitamins, minerals, and variable degree of different vegetable protein and energy sources such as soya, pea and wheat. Sampled feed concentrates were composed of wheat, corn and barley. The roughage source was either mixed straw [wheat straw in 11 out of 15 farms, mix of wheat and rapeseed straw (2/15) or maize silage (2/15)]. Each time two subsamples of $250 \mathrm{~g}$ were taken in three bags (of $20 \mathrm{~kg}$ ) of the feed concentrate, at two different locations per bag $(n=6)$. For the roughage source, three bags of mixed straw were sampled at two different locations $(n=6)$, and maize silage were sampled at three different locations $(n=3)$. Finally, milk replacer samples were collected at three different moments whilst running out of the silo $(n=3)$. All samples were kept at $<-15{ }^{\circ} \mathrm{C}$ until analysis. Subsequently, the subsamples were thawed and pooled per farm per feed component (milk replacer, roughage and feed concentrate) and analyzed for mycotoxin contamination.

\section{Analysis of milk replacer samples}

Chemicals, products and reagents Water was of high-performance liquid chromatography (HPLC) grade [generated by a Milli-Q Gradient purification system (Millipore, Billerica, MA, USA)]. Methanol (MeOH, ULC-MS), acetonitrile (ACN, LC-MS) and acetic acid (AA, ULC-MS) were supplied by Biosolve B.V. (Valkenswaard, The Netherlands).

Analytical standards of $\mathrm{AFB}_{1}, \mathrm{AFB}_{2}, \mathrm{DON}, \mathrm{FB}_{1}, \mathrm{FB}_{2}$, OTA, T-2 and ZEN were purchased from Sigma-Aldrich (Bornem, Belgium). Alternariol (AOH), and alternariol 
monomethyl ether (AME) were obtained from Fermentek (Jerusalem, Israel). ${ }^{13} \mathrm{C}_{15}$-DON, ${ }^{13} \mathrm{C}_{17}$-3-ADON, ${ }^{13} \mathrm{C}_{24}$-T-2 and ${ }^{13} \mathrm{C}_{18}$-ZEN were used as internal standards (ISs) and obtained from Coring System Diagnostix GmbH (Gernsheim, Germany). The latter also provided 3-ADON and 15-ADON.

Preparation of standard solutions Stock solutions of $\mathrm{AFB}_{1}$, $\mathrm{AFB}_{2}, \mathrm{AOH}, \mathrm{AME}, \mathrm{DON}, 3-\mathrm{ADON}, 15-\mathrm{ADON}, \mathrm{T}-2$, and ZEN were prepared in $\mathrm{ACN}$ at a concentration of $1 \mathrm{mg} / \mathrm{mL}$ and stored at $<-15{ }^{\circ} \mathrm{C}$. $\mathrm{MeOH}$ was used to dissolve the standards of $\mathrm{FB}_{1}, \mathrm{FB}_{2}$ and OTA $(1 \mathrm{mg} / \mathrm{mL})$, and stock solutions were also stored at $<-15^{\circ} \mathrm{C}$. Working solutions were prepared freshly in HPLC-grade water and protected from light.

Milk replacer sample pretreatment Extraction of mycotoxins from milk replacer was performed by means of a twofold extraction procedure. Two gram of milk replacer was weighed in a falcon tube protected from light and $15 \mathrm{~mL}$ of $\mathrm{MeOH}$ were added. After 30 min extraction on a horizontal shaker, the sample was centrifuged for $10 \mathrm{~min}$ at $4000 \mathrm{~g}$ and the supernatant was collected in a separate falcon tube, also protected from light. This extraction was repeated using $15 \mathrm{~mL}$ of $\mathrm{ACN} / \mathrm{H}_{2} \mathrm{O} / \mathrm{AA}(79 / 20 / 1, \mathrm{v} / \mathrm{v})$ and the supernatant was added to the first one. The total extract was centrifuged for $5 \mathrm{~min}$ at $4000 \mathrm{~g}$ and evaporated to $4 \mathrm{~mL}$ in a separate tube. This extract was filtered through a $0.22-\mu \mathrm{m}$ PVDF filter (Millipore) and stored at $7{ }^{\circ} \mathrm{C}$ until analysis.

UPLC-MS/MS conditions The ultra-performance liquid chromatography-tandem mass spectrometry (UPLC-MS/ MS) system consisted of an Acquity ${ }^{\mathrm{TM}} \mathrm{H}$-Class chromatographic system coupled to a Xevo TQ-S ${ }^{\circledR}$ MS/MS triple quadrupole system, both from Waters (Milford, MA, USA). Chromatographic separation was performed using an Acquity CSH Fluoro-Phenyl column $(1.7 \mu \mathrm{m}$, $150 \times 2.1 \mathrm{~mm}$ i.d., waters) column set to $60^{\circ} \mathrm{C}$. The mobile phase consisted of $\mathrm{H}_{2} \mathrm{O}+0.3 \%$ AA (A) and $\mathrm{MeOH}+0.3 \%$ AA (B) at a flow-rate of $0.4 \mathrm{~mL} / \mathrm{min}$. The gradient was initiated with $0 \%$ mobile phase $\mathrm{B}$, immediately increased to $15 \% \mathrm{~B}$ and held at $15 \% \mathrm{~B}$ for $4.5 \mathrm{~min}$ and subsequently linearly increased to $60 \% \mathrm{~B}$. After $7.5 \mathrm{~min}$ at $60 \% \mathrm{~B}$, the gradient was set to $80 \% \mathrm{~B}$ for $4.5 \mathrm{~min}$ and re-equilibrated at $0 \% \mathrm{~B}$ prior to the next injection. The mass spectrometer operated at a source and desolvation temperature of $130{ }^{\circ} \mathrm{C}$ and $500{ }^{\circ} \mathrm{C}$, respectively. Depending on the compound, the electrospray ionization (ESI) interface operated in negative and positive mode alternately in each run. Multiple reaction monitoring (MRM) was used for measuring two product ions for each mycotoxin (only one product ion for the ISs). Sample tray temperature was set to $7{ }^{\circ} \mathrm{C}$ and $5 \mu \mathrm{L}$ of each sample were injected into the UPLC-MS/MS system for analysis. Data analysis was performed using the MassLynx software version 4.1 (Waters).

In-house method validation The developed method was validated in compliance with the recommendations as defined by the European Community (2002/657/EC) and with reference guidelines defined in other EU, FDA documents and IUPAC guidelines (Heitzman 1994; Thompson et al. 2002; VICH GL 49 2011) for the following parameters: specificity, linearity $\left(r^{2}\right)$, recovery $(R)$, repeatability $\left(\mathrm{RSD}_{\mathrm{r}}\right)$, reproducibility $\left(\mathrm{RSD}_{\mathrm{R}}\right)$, limit of detection (LOD) and quantification (LOQ). Matrix-matched calibration plots were constructed for the quantification of the analytes. Evaluating the linearity, the homogeneity of variance was checked before fitting the linear model. The linearity was interpreted graphically using a scatter plot. The precision was calculated in terms of the relative standard deviation (RSD). LOD was calculated as three times the standard error of the intercept, divided by the slope of the standard curve; the LOQ was determined in a similar way, differing by six times the standard error. The calculated LOD and LOQ were verified by the signal-to-noise ratio $(S / N)$, which should be more than 3 and 10 , respectively, according to the IUPAC guidelines (Thompson et al. 2002).

For all mycotoxins studied, the criteria of linearity and specificity were fulfilled. Average $R$ varied between 85.1 and $108.4 \%$ which is within the acceptance criteria for recovery (80-110\%) as specified in Commission Decision 2002/657/EC. RSD $\mathrm{R}_{\mathrm{r}}$ and $\mathrm{RSD}_{\mathrm{R}}$ ranged between 0.4 and $12.5 \%$ and between 1.5 and $13.8 \%$, respectively. LOD was calculated as three times the standard error of the intercept, divided by the slope of the standard curve; the LOQ was determined in a similar way, differing by six times the standard error. The calculated LOD and LOQ were verified by the signal-to-noise ratio $(S / N)$, which should be more than 3 and 10, respectively, according to the IUPAC guidelines (Thompson et al. 2002). The LOD and LOQ values were within the range of $1-86 \mu \mathrm{g} / \mathrm{kg}$ and $2-171 \mu \mathrm{g} /$ $\mathrm{kg}$, respectively (Supplementary Tables 2 and 3).

\section{Analysis of roughage and feed concentrate samples}

Sample preparation and LC-MS/MS analysis was performed as previously described (Monbaliu et al. 2010). The following mycotoxins were analyzed: $\mathrm{AFB}_{1}, \mathrm{AFB}_{2}$, $\mathrm{AFG}_{1}$ and $\mathrm{AFG}_{2}$, altenuene, $\mathrm{AOH}, \mathrm{AME}, \mathrm{DON}, 3-\mathrm{ADON}$, 15-ADON, diacetoxyscirpenol, enniatin $\mathrm{B}$ (ENNB), $\mathrm{FB}_{1}$, $\mathrm{FB}_{2}, \mathrm{FB}_{3}$, fusarenon- $\mathrm{X}$, neosolaniol, nivalenol, OTA, roquefortine-C, sterigmatocystin, T-2, HT-2 and ZEN (Monbaliu et al. 2010). 


\section{Toxicokinetic study of DON and its acetylated metabolites}

\section{Animal trial}

A toxicokinetic study was performed with two fully ruminating male calves [Holstein Friesian, 5 months old, mean body weight $(\mathrm{BW})$ of $80 \pm 5 \mathrm{~kg}$ ] and two non-ruminating male calves (Holstein Friesian, 1 month old, $49 \pm 3 \mathrm{~kg} \mathrm{BW}$ ). Animals were obtained from a commercial breeder at the age of 2 weeks, and individually housed at the experimental unit of the Faculty of Veterinary Medicine of Ghent University until the experiment. Ruminating calves were fed milk replacer complemented with roughage and concentrate feed until the age of 12 weeks. After weaning they were given roughage (hay and straw) and water ad libitum, as well as $1 \mathrm{~kg}$ of commercial calf feed concentrate (Kalvermix, Van Huffel, Nevele, Belgium) daily until 1 week before the start of the experiment. During the 1 week acclimatization period prior to the experiment and during the study period ruminating calves received only hay and water ad libitum. Nonruminating calves were fed $2 \mathrm{~L}$ of a solution of a commercial milk replacer (110 g/L; Vitaspray ${ }^{\mathrm{TM}}$, Vitamex, Drongen, Belgium) three times daily from arrival at the test facility until the end of the study period. Mycotoxin contamination of the administered milk replacer, concentrate feed and hay was also analyzed as described under section "Analysis of milk replacer samples" and "Analysis of roughage and feed concentrate samples". No mycotoxins were detected. Each animal received successively a single bolus of DON $(120 \mu \mathrm{g} /$ $\mathrm{kg} \mathrm{BW}$ ), or 15-ADON (50 $\mu \mathrm{g} / \mathrm{kg} \mathrm{BW})$, or 3-ADON (25 $\mu \mathrm{g} / \mathrm{kg}$ $\mathrm{BW}$ ) by intravenous (IV) injection in the right jugular vein or per os by oesophageal tube (PO) in a crossover design with a 4-day wash-out period between each administration. The administered doses were based on the maximum contamination level of the selected mycotoxins (section "Occurrence of mycotoxins in veal feed components") and the average daily feed intake. DON, 15-ADON, and 3-ADON had $>99 \%$ purity (Fermentek, Jerusalem, Israel). The mycotoxins were dissolved in analytical grade ethanol (EtOH, Merck, Brussels, Belgium), yielding a stock solution of $10 \mathrm{mg} / \mathrm{mL}$. The DON, 15-ADON, or 3-ADON bolus was prepared immediately prior to administration by further diluting the stock solution with $0.9 \% \mathrm{NaCl}$ solution up to a concentration of $1 \mathrm{mg} / \mathrm{mL}$. After oral administration of the toxins, $500 \mathrm{~mL}$ of tap water was administered to flush the gavage tube. Animals were deprived of feed $12 \mathrm{~h}$ before the administration of the mycotoxin until $12 \mathrm{~h}$ post-administration (p.a.). Following mycotoxin bolus administration, blood samples $(4 \mathrm{~mL})$ were collected in heparinized tubes from an $18 \mathrm{G}$ catheter in the left jugular vein before administration $(t=0)$, at 5, 15, 30 and 45 min p.a. and at 1, 1.5, 2, 2.5, 3, 4, 6, 8, 10, 12, 24, 36, 48, 72 and 96 h p.a. Blood samples were centrifuged $(2851 \mathrm{~g}$,
$10 \mathrm{~min}, 4{ }^{\circ} \mathrm{C}$ ) and plasma was stored at $\leq-15^{\circ} \mathrm{C}$ until further analysis. Urine samples were collected after manual stimulation of the praeputium before administration $(t=0)$ and at 3, 6, 9, 12, 24, 36, 48, 72 and $96 \mathrm{~h}$ p.a., and stored at $\leq-15{ }^{\circ} \mathrm{C}$ until further analysis. The animal experiment was approved by the Ethical Committee of the Faculty of Veterinary Medicine and the Faculty of Bioscience Engineering of Ghent University (EC2014/93-approved on 4/09/2014).

\section{Analysis of DON and metabolites in calf plasma}

Chemicals, products and reagents The analytical standards of DON, 3-ADON and 15-ADON were obtained from Fermentek. The standard of DOM-1 was purchased from Sigma-Aldrich (Bornem, Belgium). The IS, ${ }^{13} \mathrm{C}_{15}$-DON was obtained from Romer Labs (Tulln, Austria). The analytical standard of DON-3-glucuronide (DON-3-GlcA) was synthesized as described by Fruhmann et al. (2012). DON-3-sulfate (DON-3-S), DON-15-sulfate (DON-15-S), 3-ADON-15-sulfate (3-ADON-15-S) and 15-ADON-3-sulfate (15-ADON-3-S) analytical standards were synthesized as described by Fruhmann et al. (2014). All standards were stored at $\leq-15{ }^{\circ} \mathrm{C}$. All solvents and reagents used for LC-MS/MS analysis (water, $\mathrm{MeOH}, \mathrm{ACN}$ and ammonium acetate) were of LC-MS grade and obtained from Biosolve (Valkenswaard, The Netherlands), while solvents used for sample preparation (ACN, EtOH) were of analytical grade and obtained from VWR (Leuven, Belgium). Millex ${ }^{\circledR} \mathrm{GV}$ PVDF filter units $(0.22 \mu \mathrm{m})$ were obtained from Millipore.

Preparation of standard solutions Stock solutions were prepared in EtOH (DON, 3-ADON and 15-ADON at $10 \mathrm{mg}$ / $\mathrm{mL})$. The standards of DOM- 1 and ${ }^{13} \mathrm{C}_{15}$-DON were purchased as solutions of 50 and $25 \mu \mathrm{g} / \mathrm{mL}$ in $\mathrm{ACN}$, respectively. The standards of DON-3-GlcA, DON-3-S, DON15-S, 3-ADON-15-S and 15-ADON-3-S were dissolved in ACN, yielding a stock solution of $20 \mu \mathrm{g} / \mathrm{mL}$. The stock solutions were stored at $\leq-15^{\circ} \mathrm{C}$.

Combined standard working solutions of 1.0, 0.1, 0.01 and $0.001 \mu \mathrm{g} / \mathrm{mL}$ of all mycotoxins (except the IS) were prepared by mixing an appropriate aliquot of each stock and/ or working solution, followed by further dilution in $\mathrm{MeOH}$. For the IS, a working solution of $0.1 \mu \mathrm{g} / \mathrm{mL}$ was prepared in $\mathrm{MeOH}$. The working solutions were stored at $2-8{ }^{\circ} \mathrm{C}$.

Plasma sample pretreatment Twenty-five $\mu \mathrm{L}$ of a $0.1 \mu \mathrm{g} /$ $\mathrm{mL}$ IS working solution was added to $250 \mu \mathrm{L}$ of plasma sample, followed by a vortex mixing (10 s) step. After the addition of $750 \mu \mathrm{L}$ of $\mathrm{ACN}$, the samples were vortex mixed for $30 \mathrm{~s}$ and centrifuged for $10 \mathrm{~min}$ at $8517 \mathrm{~g}$ and $4{ }^{\circ} \mathrm{C}$. The supernatant was transferred to another tube and evaporated using a gentle stream of nitrogen $\left(\mathrm{N}_{2} ; \sim 40{ }^{\circ} \mathrm{C}\right)$ till dryness. The dry residue was reconstituted in $250 \mu \mathrm{L}$ of $\mathrm{H}_{2} \mathrm{O} / \mathrm{MeOH}$ 
$(95 / 5, \mathrm{v} / \mathrm{v})$, vortexed for $15 \mathrm{~s}$, passed through a $0.22 \mu \mathrm{m}$ Millex ${ }^{\circledR}$ GV-PVDF syringe filter and transferred into a vial. A $10-\mu \mathrm{L}$ aliquot was injected onto the UPLC-MS/MS instrument.

UPLC-MS/MS conditions UPLC-MS/MS conditions were as previously described in section "Analysis of milk replacer samples". Chromatographic separation was achieved on an Acquity UPLC ${ }^{\circledR}$ CS Fluoro-Phenyl column $(1.7 \mu \mathrm{m}$; $150 \times 2.1 \mathrm{~mm}$ i.d.) in combination with an Acquity Vanguard pre-column of the same type, both from Waters. The mobile phase A consisted of $20 \mathrm{mM}$ ammonium acetate in water, while the mobile phase $\mathrm{B}$ was $\mathrm{MeOH}$. The gradient was initiated with $1 \%$ mobile phase B for $0.5 \mathrm{~min}$ $(0-0.5 \mathrm{~min})$, subsequently linearly increased to $15 \% \mathrm{~B}$ over $0.5 \mathrm{~min}(0.5-1.0 \mathrm{~min})$ and held at $15 \%$ for $4.5 \mathrm{~min}$ (1.0-5.5 min), followed by a linear increase to $60 \% \mathrm{~B}$ over $0.5 \mathrm{~min}(5.5-6.0 \mathrm{~min})$ and immediately followed by a linear increase to $99 \%$ B over $2.5 \mathrm{~min}(6.0-8.5 \mathrm{~min})$. The column was rinsed at $99 \% \mathrm{~B}$ for $1.5 \mathrm{~min}(8.5-10.0 \mathrm{~min})$, followed by a linear gradient to the initial conditions (10.0-10.2 $\mathrm{min})$ and a re-equilibration for $4.8 \mathrm{~min}(10.2-15.0 \mathrm{~min})$ at $1 \% \mathrm{~B}$ prior to the next injection. The flow-rate was $0.4 \mathrm{~mL} / \mathrm{min}$. The temperatures of the column oven and autosampler tray were set to $45^{\circ} \mathrm{C}$ and $6{ }^{\circ} \mathrm{C}$, respectively.

The UPLC column effluent was interfaced to a Xevo TQ-S ${ }^{\circledR}$ MS/MS system, equipped with an ESI probe operating in the positive or negative mode (all from Waters). Depending on the compound, the ESI interface operated in negative and positive mode alternately in each run. In combination with the mobile phase $(50 \%$ A, $50 \%$ B, flowrate: $200 \mu \mathrm{L} / \mathrm{min}$ ) instrument parameters were optimized by direct infusion of working solutions of $1.0 \mu \mathrm{g} / \mathrm{mL}$ of each compound (flow-rate: $20 \mu \mathrm{L} / \mathrm{min}$ ). The following parameters were used: capillary voltage: $3.0 \mathrm{kV}$, source offset: $60 \mathrm{~V}$, desolvation temperature: $600{ }^{\circ} \mathrm{C}$, desolvation gas: $800 \mathrm{~L} / \mathrm{h}$, cone gas: $150 \mathrm{~L} / \mathrm{h}$, nebulizer pressure: $7.0 \mathrm{bar}, \mathrm{LM}$ resolution 1 and 2: 2.72 and 2.86, respectively, HM resolution 1 and 2: 14.90 and 15.15 , respectively, ion energy 1 and 2: 0.2 and 0.7 , respectively, collision gas flow: $0.2 \mathrm{~mL} / \mathrm{min}$. MS/MS acquisition was performed in the MRM mode. The MRM transitions that were monitored for DON and metabolites and the IS are shown in Supplementary Table 4.

In-house method validation Method validation was as previously described in section "Analysis of milk replacer samples". The following parameters were evaluated for all analytes of interest in calf plasma: linearity between 0.1 and $200 \mathrm{ng} / \mathrm{mL}$; within-run and between-run accuracy and precision at a concentration level of 5.0 and $50.0 \mathrm{ng} /$ $\mathrm{mL}$; LOQ and LOD, respectively, DON: 0.2 and $0.01 \mathrm{ng} /$ mL, 3-ADON: 0.1 and $0.015 \mathrm{ng} / \mathrm{mL}, 15-\mathrm{ADON}$ : 5.0 and $1.74 \mathrm{ng} / \mathrm{mL}$, DON-3-S/DON-15-S: 0.2 and $0.01 \mathrm{ng} / \mathrm{mL}$,
3-ADON-15-S: 0.5 and $0.004 \mathrm{ng} / \mathrm{mL}, 15-\mathrm{ADON}-3-\mathrm{S}: 0.2$ and $0.006 \mathrm{ng} / \mathrm{mL}$. DOM-1: 0.5 and $0.08 \mathrm{ng} / \mathrm{mL}$, DON-3GlcA: 5.0 and $0.612 \mathrm{ng} / \mathrm{mL}$; stability during 3 freeze-thaw cycles, carry-over and specificity. The results are shown in Supplementary Table 5 and fell within the acceptance ranges.

Toxicokinetic analysis Toxicokinetic analysis was performed using a non-compartmental model (WinNonlin 6.3, Pharsight, USA). Plasma levels below LOQ were not included in the analysis. Following major toxicokinetic parameters of DON and 3-ADON following IV administration were calculated: $\mathrm{C}_{0}$, plasma concentration at time $=0 \mathrm{~h}$; $\mathrm{AUC}_{0-t}$, area under the plasma concentration-time curve from time $0 \mathrm{~h}$ to last sampling point with a plasma concentration above LOQ (DON: ruminating calves $8 \mathrm{~h}$ and nonruminating calves $48 \mathrm{~h}, 3$-ADON: ruminating calves $2.5 \mathrm{~h}$ and non-ruminating $2 \mathrm{~h}$ p.a., respectively); $\mathrm{AUC}_{0-\infty}$, area under the plasma concentration-time curve from time $0 \mathrm{~h}$ to infinity; AUCs were calculated using the linear up-log down method; $\mathrm{Cl}$, total body clearance; $k_{\mathrm{el}}$, elimination rate constant; $T_{1 / 2 \mathrm{e}}$, half-life of elimination; $\mathrm{Vd}$, volume of distribution. Since $15-A D O N$ was only measured following IV administration until 15 min after administration, and even not measured following PO administration, toxicokinetic analysis could not be performed. Additionally, following toxicokinetic parameters of DON after PO administration were calculated: $C_{\max }$, maximum plasma concentration, $T_{\max }$, time to maximal plasma concentration, and the absolute oral bioavailability $(F)$ of DON according to the formula: $\left[F(\%)=\left(\mathrm{AUC}_{0-t \text { DON PO }} / \mathrm{AUC}_{0-t \text { DON IV }}\right) \times 100\right]$. Since 3-ADON was either not detected or below LOQ in ruminating calves, and only traces of 3-ADON were detected in plasma of non-ruminating calves, toxicokinetic analysis could not be performed. Taking into account that per group $n=2$, no statistical analysis has been performed.

\section{Analysis of DON and metabolites in calf urine}

Chemicals, products and reagents Analytical standards of DON, DOM-1, 3-ADON, 15-ADON and ${ }^{13} \mathrm{C}_{15}$-DON (IS) were obtained from Sigma Aldrich (Bornem, Belgium). The analytical standard of DON-3-GlcA was synthesized as described by Fruhmann et al. (2012) and kindly supplied by Dr. Huybrechts (CODA-CERVA). All standards were stored at $\leq-15{ }^{\circ} \mathrm{C}$. Water was of HPLC grade (generated by a Milli-Q Gradient purification system (Millipore)). $\mathrm{MeOH}$ was of LC-MS grade and obtained from Biosolve, while ACN was of analytical grade and obtained from VWR. Acetic acid (glacial, 100\%) and formic acid (98-100\%) were obtained from Merck (Darmstadt, Germany). Magnesium sulphate anhydrous (>99.5\%) was obtained from Alfa 
Aesar (Haverhill, Massachusetts, USA). Sodium chloride $(>99.5 \%)$ was obtained from VWR.

Preparation of standard solutions Stock solutions were prepared in MeOH (DON, DOM-1, 3-ADON and 15-ADON at $10 \mu \mathrm{g} / \mathrm{mL}$ ). The IS ${ }^{13} \mathrm{C}_{15}$-DON was purchased as a solution of $25 \mu \mathrm{g} / \mathrm{mL}$ in ACN. The standard of DON-3-GlcA was delivered as a solution of $1 \mu \mathrm{g} / \mathrm{mL}$ in ACN. Stock solutions were stored at $\leq-15^{\circ} \mathrm{C}$. Working solutions of 1.0 , $0.1,0.01$ and $0.001 \mu \mathrm{g} / \mathrm{mL}$ containing a mixture of standard solutions of all mycotoxins (except the IS) were prepared by mixing an appropriate aliquot of each stock and/or working solution, followed by further dilution. For the IS, a working solution of $0.1 \mu \mathrm{g} / \mathrm{mL}$ was prepared in $\mathrm{MeOH}$. Working solutions were stored at $2-8{ }^{\circ} \mathrm{C}$.

Urine sample preparation To $2.0 \mathrm{~mL}$ of urine sample $100 \mu \mathrm{L}$ of a $0.1 \mu \mathrm{g} / \mathrm{mL}$ IS working solution were added, followed by a vortex mixing $(10 \mathrm{~s})$ step. Then, $18 \mathrm{~mL}$ of ACN/water/formic acid (52/45/3, v/v) were added and subsequently, $4 \mathrm{~g}$ of anhydrous magnesium sulphate and $1 \mathrm{~g}$ of sodium chloride were added. Samples were vigorously shaken by hand, and subsequently placed on an Agitator (Agitelec, Paris, France) decanter overhead shaker for $30 \mathrm{~min}$, and centrifuged at $4000 \mathrm{~g}$ for $6 \mathrm{~min}$. Five $\mathrm{mL}$ of the organic phase were evaporated to dryness under a gentle nitrogen stream at $40{ }^{\circ} \mathrm{C}$. Finally, the residue was redissolved in $500 \mu \mathrm{L}$ of injection solvent $(\mathrm{MeOH} /$ water, 10/90, $\mathrm{v} / \mathrm{v}$ ), vortexed for $15 \mathrm{~s}$, passed through a $0.22 \mu \mathrm{m}$ Millex ${ }^{\circledR}$ GV-PVDF syringe filter and transferred to a vial. A $10-\mu \mathrm{L}$ aliquot was injected onto the column.

UPLC-MS/MS conditions UPLC-MS/MS conditions were as previously described in section "Analysis of milk replacer samples". Data acquisition and processing have been performed with MassLynx ${ }^{\mathrm{TM}}$ version 4.1 and QuanLynx ${ }^{\circledR}$ version 4.1 software (Waters). A Waters Acquity UPLC ${ }^{\circledR}$ HSS T3 $(1.8 \mu \mathrm{m}, 100 \times 2.1 \mathrm{~mm}$ i.d. $)$ column was used. The mobile phase A consisted of $\mathrm{H}_{2} \mathrm{O} / \mathrm{AA}(99.9 / 0.1$, v/v) and the mobile phase B was MeOH/AA $(99.9 / 0.1, \mathrm{v} / \mathrm{v})$. The gradient was initiated with $1 \%$ mobile phase $\mathrm{B}$ for $0.5 \mathrm{~min}$, subsequently linearly increased to $45 \%$ B over $5.5 \mathrm{~min}$, followed by a linear increase to $99 \%$ B over $1.5 \mathrm{~min}$, finally the gradient was set to $1 \% \mathrm{~B}$ for $1.5 \mathrm{~min}$ and re-equilibrated at $1 \% \mathrm{~B}$ prior to the next injection. The flow-rate was $0.4 \mathrm{~mL} /$ min. The temperatures of the column oven and autosampler tray were set to $40{ }^{\circ} \mathrm{C}$ and $6{ }^{\circ} \mathrm{C}$, respectively.

The Xevo TQ- $\mathrm{S}^{\circledR}$ MS/MS system was equipped with an ESI probe operating in the positive or negative mode. Depending on the compound, the ESI interface operated in negative and positive mode alternately in each run. The following parameters were used: capillary voltage: $3.0 \mathrm{kV}$, source offset: $60 \mathrm{~V}$, desolvation temperature: $600{ }^{\circ} \mathrm{C}$, desolvation gas: $500 \mathrm{~L} / \mathrm{h}$, cone gas: $50 \mathrm{~L} / \mathrm{h}$, nebulizer pressure: $9.0 \times 10^{-6}$ bar. Two selected MRM transitions with a specific dwell-time were optimized for each analyte, in order to increase the sensitivity and the selectivity of the mass spectrometric conditions (Supplementary Table 6).

In-house method validation Method validation was as previously described in section "Analysis of milk replacer samples". Results of the validation characteristics of the LC-MS/MS method were in compliance with the criteria mentioned in European Commission Decision (2002/657/ EC) (Supplementary Table 7). DON-15-GlcA was only estimated using the DON-3-GlcA reference standard whereby the concentration of DON-15-GlcA was corrected for the higher response by a factor of 1.88 (Warth et al. 2012).

\section{Results}

\section{Occurrence of mycotoxins in veal feed components}

About $13 \%$ of the milk replacer samples were contaminated with $\mathrm{FB}_{1}$ and $\mathrm{FB}_{2}$, with an average contamination level of $32 \pm 7$ and $13 \pm 1 \mu \mathrm{g} / \mathrm{kg}$, respectively. None of the other mycotoxins included in the analytical method were found in these milk replacer samples.

All roughage and feed concentrate samples were contaminated with at least one mycotoxin, ranging from 1 to 11 different mycotoxins ( 5 on average) in the concentrate mixture samples and 1-6 different mycotoxins ( 3 on average) in the roughage samples (Table 2). DON was most prevalent, contaminating $80 \%$ of the roughage samples [average concentration in positives on fresh matter basis (FM): $637 \pm 621 \mu \mathrm{g} /$ $\mathrm{kg}$, max. $1818 \mu \mathrm{g} / \mathrm{kg}$ ], and all concentrate mixture samples $(411 \pm 156 \mu \mathrm{g} / \mathrm{kg}(\mathrm{FM}), \max .693 \mu \mathrm{g} / \mathrm{kg})$. Also the DON conjugates 3-ADON and 15-ADON were present in at least $40 \%$ of the roughage and feed concentrate samples. Maximum contamination levels of $450 \mu \mathrm{g} / \mathrm{kg}$ and $825 \mu \mathrm{g} / \mathrm{kg}$ for 3-ADON and 15-ADON, respectively, were found in roughage. However, maximum levels of 3-ADON and 15-ADON in feed concentrate were lower, $46 \mu \mathrm{g} / \mathrm{kg}$ and $132 \mu \mathrm{g} / \mathrm{kg}$, respectively. Besides, also ENNB was highly prevalent, with high maximum contamination levels of $2398 \mu \mathrm{g} / \mathrm{kg}$ and $553 \mu \mathrm{g} / \mathrm{kg}$ in roughage and feed concentrate samples, respectively.

\section{Toxicokinetic study of DON, 3-ADON and 15-ADON}

No adverse effects were observed during the animal trial following PO and IV bolus administration of DON, 3-ADON or 15-ADON. 
Table 2 Detected mycotoxins in roughage (1 pooled sample/farm) and feed concentrate samples (1 pooled sample/farm), collected on 15 Flemish veal farms

\begin{tabular}{|c|c|c|c|c|c|c|}
\hline & \multicolumn{3}{|c|}{ Roughage $(n=15)$} & \multicolumn{3}{|c|}{ Feed concentrate $(n=15)$} \\
\hline & $\begin{array}{l}\% \text { Positive } \\
\text { samples }\end{array}$ & $\begin{array}{l}\text { Average concentration } \\
\text { in positives } \pm S D\end{array}$ & $\begin{array}{l}\text { Maximum concen- } \\
\text { tration }(\mu \mathrm{g} / \mathrm{kg})\end{array}$ & $\begin{array}{l}\% \text { Positive } \\
\text { samples }\end{array}$ & $\begin{array}{l}\text { Average concentration } \\
\text { in positives } \pm S D\end{array}$ & $\begin{array}{l}\text { Maximum } \\
\text { concentration } \\
(\mu \mathrm{g} / \mathrm{kg})\end{array}$ \\
\hline & \multicolumn{3}{|l|}{$(\mu \mathrm{g} / \mathrm{kg})$} & \multicolumn{3}{|l|}{$(\mu \mathrm{g} / \mathrm{kg})$} \\
\hline Alternariol & 27 & $64 \pm 67$ & 164 & 7 & 15 & 15 \\
\hline Deoxynivalenol & 80 & $637 \pm 621$ & 1818 & 100 & $411 \pm 156$ & 693 \\
\hline 3-Acetyldeoxynivalenol & 40 & $149 \pm 150$ & 450 & 40 & $37 \pm 12$ & 46 \\
\hline 15-Acetyldeoxynivalenol & 40 & $438 \pm 422$ & 825 & 87 & $68 \pm 34$ & 132 \\
\hline Diacetoxyscirpenol & 7 & 4 & 4 & 13 & $2 \pm 0$ & 2 \\
\hline Enniatin B & 73 & $652 \pm 721$ & 2398 & 60 & $152 \pm 158$ & 553 \\
\hline Fumonisin $\mathrm{B}_{1}$ & ND & & & 40 & $134 \pm 80$ & 285 \\
\hline Fumonisin $\mathrm{B}_{2}$ & ND & & & 20 & $125 \pm 137$ & 283 \\
\hline Fumonisin $\mathrm{B}_{3}$ & ND & & & 13 & $74 \pm 28$ & 94 \\
\hline HT-2 toxin & ND & & & 7 & 21 & 21 \\
\hline Neosolaniol & ND & & & 13 & $11 \pm 2$ & 13 \\
\hline Nivalenol & 53 & $78 \pm 43$ & 163 & 73 & $85 \pm 43$ & 157 \\
\hline $\mathrm{T}-2$ toxin & ND & & & 13 & $26 \pm 22$ & 44 \\
\hline Zearalenone & ND & & & 27 & $144 \pm 125$ & 289 \\
\hline
\end{tabular}

Concentrations expressed on fresh matter basis, ND: not detected; SD: standard deviation; fusarenon-X; aflatoxin $\mathrm{B}_{1}, \mathrm{~B}_{2}, \mathrm{G}_{1}$ and $\mathrm{G}_{2}$; alternariol methyl ether; sterigmatocystin; ochratoxin $\mathrm{A}$ and roquefortine $\mathrm{C}$ were not detected

\section{Plasma concentration}

Figure 2 shows the plasma concentration-time profile of DON and DON-3-GlcA following IV and PO administration of DON. The major toxicokinetic parameters are shown in Table 3. The absolute oral bioavailability $(F)$ of DON following PO administration was remarkably lower in ruminating calves than in the non-ruminating calves, $4.1 \pm 4.5 \%$ versus $50.7 \pm 33.0 \%$, respectively. Clearance of DON following IV administration was similar in ruminating and nonruminating calves, $1.4 \pm 0.1$ and $1.7 \pm 0.1 \mathrm{~L} / \mathrm{h} / \mathrm{kg}$, respectively (Table 3 ). On the other hand, the $V_{\mathrm{d}}$ was $2.2 \pm 0.1 \mathrm{~L} / \mathrm{kg}$ and $4.8 \pm 1.0 \mathrm{~L} / \mathrm{kg}$ in ruminating calves and non-ruminating calves, respectively (Table 3 ). This led to a difference in elimination half-life. Following PO DON administration the $C_{\max }$ of $2.97 \pm 1.19 \mathrm{ng}$ DON $/ \mathrm{mL}$ was reached after $1 \mathrm{~h}\left(T_{\max }\right)$ in the non-ruminating calves. In one ruminating calf a $C_{\max }$ of $9.18 \mathrm{ng} \mathrm{DON} / \mathrm{mL}$ was already reached after $0.08 \mathrm{~h}\left(T_{\max }\right)$, while in the other calf only a $C_{\max }$ of $0.38 \mathrm{ng} \mathrm{DON} / \mathrm{mL}$ was only reached after $3 \mathrm{~h}\left(T_{\max }\right)$ following PO DON administration. DON was rapidly metabolized to DON-3-GlcA following oral exposure or IV administration (Fig. 2b). Following IV administration DON was metabolized to DON-3-GlcA in ruminating and non-ruminating calves (Table 4).

Figure 3 shows the plasma concentration-time profile of 3-ADON, DON and DON-3-GlcA following IV and $\mathrm{PO}$ administration of 3-ADON. Plasma levels of 3-ADON,
DON, or DON-3-GlcA following PO 3-ADON administration were either not detected or below LOQ in ruminating calves, and only traces of 3-ADON were detected in plasma of non-ruminating calves. Immediately following oral exposure or IV administration, 3-ADON was hydrolyzed to DON and subsequently metabolized to DON-3GlcA (Fig. 3). Following IV administration of 3-ADON, DON-3-GlcA was longer detected in the plasma compared to DON and 3-ADON (Fig. 3). No further remarkable differences between ruminating and non-ruminating animals were observed for the main toxicokinetic parameters of 3-ADON following IV exposure (Table 3 ) and the biotransformation to DON-3-GlcA (Table 4).

Figure 4 shows the plasma concentration-time profile of DON and DON-3-GlcA following IV administration of 15-ADON. In both groups, plasma levels of 15-ADON above the LOQ were only measured in samples of 5 and $15 \mathrm{~min}$ post-IV administration (range $6.31-24.11 \mathrm{ng} / \mathrm{mL}$ ). Plasma levels of 15-ADON, DON and DON-3-GlcA following PO 15-ADON administration were not detected or below LOQ in both types of calves. Similarly to 3-ADON, following IV administration, 15-ADON was rapidly hydrolyzed to DON and subsequently metabolized to DON-3GlcA (Fig. 4). Following IV administration of 15-ADON, DON-3-GlcA was longer detected in the plasma compared to DON (Fig. 4). The further biotransformation to DON3-GlcA was similar in both groups, demonstrated by the 
Fig. 2 Plasma concentrationtime profile of a deoxynivalenol (DON) and $\mathbf{b}$ its phase II metabolite, deoxynivalenol3-glucuronide (DON-3-GlcA) after intravenous (IV) and oral (PO) administration of $120 \mu \mathrm{g}$ $\mathrm{DON} / \mathrm{kg}$ bodyweight to two ruminating calves and two nonruminating calves. The inserts emphasize the plasma concentration-time profiles of the first $4 \mathrm{~h}$ following administration. Values are presented as means of $n=2+\mathrm{SD}$
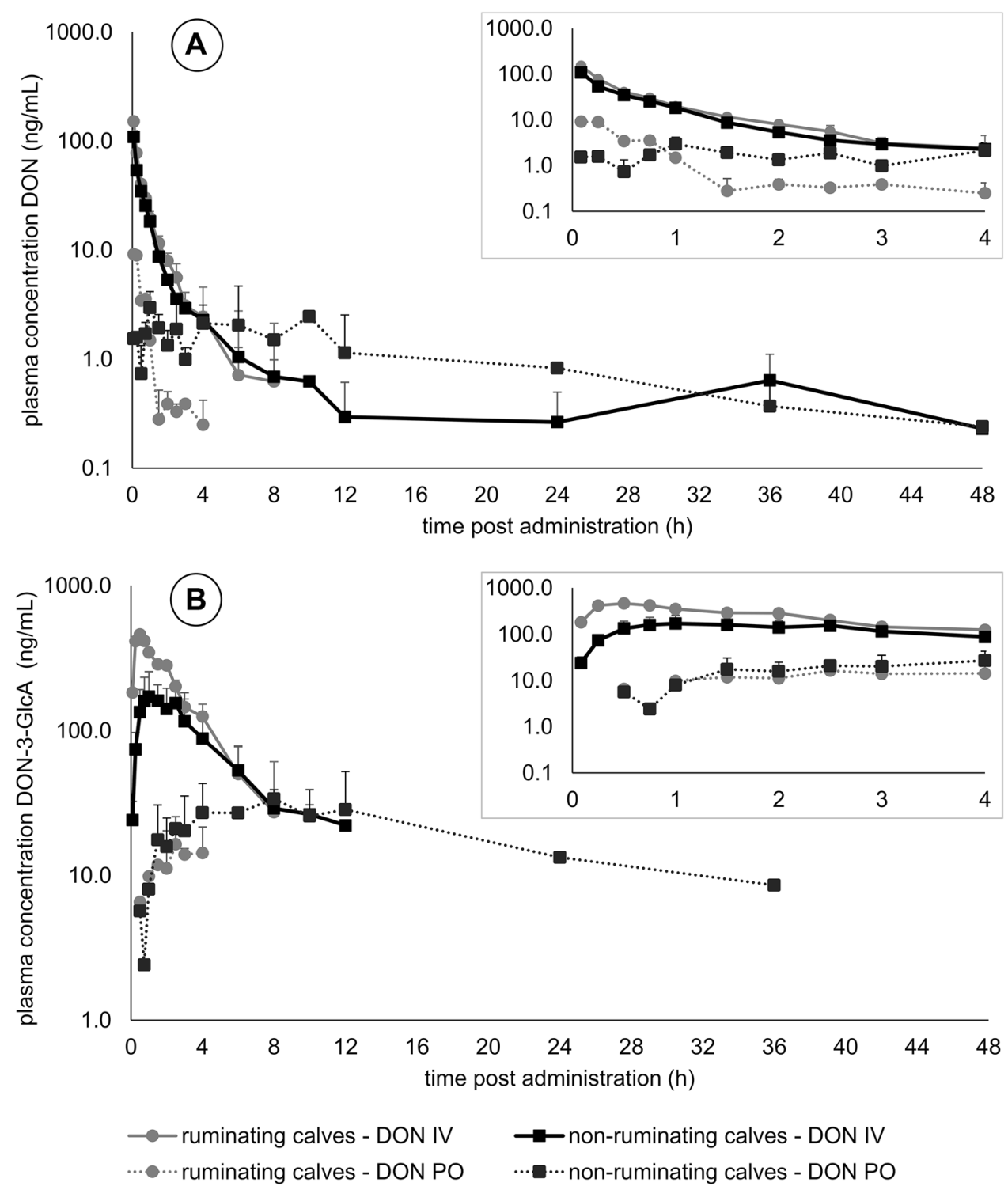

$\mathrm{AUC}_{0-t}$ of DON-3-GlcA, 81.9 \pm 60.8 and 57.8 \pm 25.9 (h ng)/ $\mathrm{mL}$ in ruminating and non-ruminating calves, respectively (Table 4). DOM-1, nor DON-sulfates, could not be detected in plasma following IV or PO administration of DON, 3-ADON, or 15-ADON.

\section{Urine concentration}

Figure 5 shows the urine concentration-time profile of DON (A), sum of 3- and 15-ADON (B), DON-3-GlcA (C), DON15-GlcA (D), and DOM-1 (E). In both groups, following IV administration of DON, DON was only detected in the urine until $9 \mathrm{~h}$ p.a. The maximum urinary concentration of DON following IV DON administration was $547 \pm 64 \mathrm{ng} /$ $\mathrm{mL}$ and $2145 \pm 2756 \mathrm{ng} / \mathrm{mL}$, in ruminating and non-ruminating calves, respectively (Fig. 5a). Remarkably, no urinary DON was detected in ruminating calves following oral DON administration. In contrast, low levels of DON were demonstrated in the urine of non-ruminating calves following DON PO. Following IV or PO administration of 3-ADON and 15-ADON low concentrations of ADONs were found in both groups, ranging from 0.5 to $15 \mathrm{ng} / \mathrm{mL}$ (Fig. $5 \mathrm{~b}$ ).

Non-ruminating 1-month-old calves were characterized by a higher urinary level of DON-3-GlcA compared to ruminating 5-month-old calves following IV administration of DON $(195 \pm 42 \mathrm{ng} / \mathrm{mL}$ versus $54 \pm 48 \mathrm{ng} / \mathrm{mL}), 15-A D O N$ $(30 \pm 31 \mathrm{ng} / \mathrm{mL}$ versus $27 \pm 16 \mathrm{ng} / \mathrm{mL})$, or $3-A D O N$

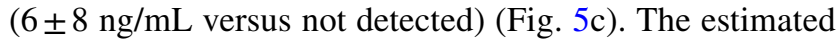
urinary concentration of DON-15-GlcA was low in both groups (Fig. 5d).

In contrast to DON-3-GlcA, only traces of DOM-1 were detected in non-ruminating calves following IV or PO administration of DON, 15-ADON or 3-ADON, while higher levels were observed in ruminating calves (Fig. 5e). 
Table 3 Main toxicokinetic parameters of deoxynivalenol (DON) and 3-acetyl-deoxynivalenol (3-ADON) following intravenous (IV) administration of $120 \mu \mathrm{g} \mathrm{DON} / \mathrm{kg}$ BW or $25 \mu \mathrm{g} 3-\mathrm{ADON} / \mathrm{kg} \mathrm{BW}$, respectively, to ruminating (RUM, $n=2$ ) and non-ruminating (nonRUM, $n=2$ ) calves

\begin{tabular}{|c|c|c|c|c|}
\hline & \multicolumn{2}{|l|}{ DON } & \multicolumn{2}{|l|}{ 3-ADON } \\
\hline & RUM & Non-RUM & RUM & Non-RUM \\
\hline$C_{0}(\mathrm{ng} / \mathrm{mL})$ & $151.7 \pm 9.8$ & $109.5 \pm 15.2$ & $23.4 \pm 5.1$ & $10.4 \pm 1.9$ \\
\hline $\begin{array}{l}\mathrm{AUC}_{0-t}((\mathrm{~h} \mathrm{ng}) / \\
\mathrm{mL})\end{array}$ & $88.0 \pm 2.3$ & $68.6 \pm 0.4$ & $8.1 \pm 1.9$ & $4.0 \pm 0.1$ \\
\hline $\begin{array}{l}\mathrm{AUC}_{0-\infty}((\mathrm{h} n g) / \\
\mathrm{mL})\end{array}$ & $89.1 \pm 2.5$ & $71.7 \pm 1.8$ & $8.1 \pm 1.9$ & $4.2 \pm 0.3$ \\
\hline $\mathrm{Cl}(\mathrm{L} / \mathrm{h} / \mathrm{kg})$ & $1.4 \pm 0.1$ & $1.7 \pm 0.1$ & $3.2 \pm 0.8$ & $6.0 \pm 0.5$ \\
\hline$k_{\mathrm{el}}\left(\mathrm{h}^{-1}\right)$ & $0.6 \pm 0.1$ & $0.4 \pm 0.1$ & $2.1 \pm 0.8$ & $2.7 \pm 3.0$ \\
\hline$T_{1 / 2 \mathrm{el}}(\mathrm{h})$ & $1.1 \pm 0.1$ & $2.0 \pm 0.5$ & $0.4 \pm 0.1$ & $0.7 \pm 0.8$ \\
\hline$V_{\mathrm{d}}(\mathrm{L} / \mathrm{kg})$ & $2.2 \pm 0.1$ & $4.8 \pm 1.0$ & $1.6 \pm 0.2$ & $5.5 \pm 6.0$ \\
\hline
\end{tabular}

Values are presented as means $\pm \mathrm{SD}$

$C_{0}$, plasma concentration at time $=0 \mathrm{~h} ; \mathrm{AUC}_{0-t}$, area under the plasma concentration-time curve from time $0 \mathrm{~h}$ to last sampling point with a plasma concentration above LOQ (DON: RUM $8 \mathrm{~h}$ and non-RUM $48 \mathrm{~h}, 3-\mathrm{ADON}$ : RUM $2.5 \mathrm{~h}$ and non-RUM $2 \mathrm{~h}$ post-administration, respectively); $\mathrm{AUC}_{0-\infty}$, area under the plasma concentration-time curve from time $0 \mathrm{~h}$ to infinity; $\mathrm{Cl}$, total body clearance; $k_{\mathrm{e}}$, elimination rate constant; $T_{1 / 2 \mathrm{el}}$, half-life of elimination; $V_{\mathrm{d}}$, volume of distribution

Table 4 Area under the plasma concentration-time curve $\left(\mathrm{AUC}_{0-t}\right)$ (h ng)/mL of deoxynivalenol (DON) and deoxynivalenol-3-glucuronide (DON-3-GlcA) following intravenous (IV) and oral (PO) administration of DON (120 $\mu \mathrm{g} / \mathrm{kg} \mathrm{BW}), 3$-acetyl-deoxynivalenol (3-ADON) $(25 \mu \mathrm{g} / \mathrm{kg} \mathrm{BW})$, or 15 -acetyl-deoxynivalenol $(15-\mathrm{ADON})(50 \mu \mathrm{g} / \mathrm{kg}$ $\mathrm{BW}$ ) to ruminating (RUM, $n=2$ ) and non-ruminating (non-RUM, $n=2)$ calves

\begin{tabular}{|c|c|c|c|c|}
\hline \multirow{2}{*}{$\begin{array}{l}\text { Toxin (route } \\
\text { of adminis- } \\
\text { tration) }\end{array}$} & \multicolumn{2}{|l|}{ DON } & \multicolumn{2}{|l|}{ DON-3-GlcA } \\
\hline & RUM & Non-RUM & RUM & Non-RUM \\
\hline DON (IV) & $88.0 \pm 2.3$ & $68.6 \pm 0.4$ & $1343.2 \pm 166.1$ & $822.7 \pm 373.9$ \\
\hline $\mathrm{DON}(\mathrm{PO})$ & $3.6 \pm 4.0$ & $34.9 \pm 22.8$ & $91.0 \pm 33.1$ & $588.1 \pm 308.8$ \\
\hline $\begin{array}{l}\text { 3-ADON } \\
\text { (IV) }\end{array}$ & $8.6 \pm 1.8$ & $6.4 \pm 5.5$ & $122.8 \pm 77.4$ & $158.4 \pm 66.7$ \\
\hline $\begin{array}{l}\text { 3-ADON } \\
\text { (PO) }\end{array}$ & ND & $3.4 \pm 1.1$ & ND & $66.7 \pm 5.5$ \\
\hline $\begin{array}{l}\text { 15-ADON } \\
\text { (IV) }\end{array}$ & $3.2 \pm 0.4$ & $1.2 \pm 0.4$ & $81.9 \pm 60.8$ & $57.8 \pm 25.9$ \\
\hline $\begin{array}{l}\text { 15-ADON } \\
\text { (PO) }\end{array}$ & ND & ND & ND & ND \\
\hline
\end{tabular}

Values are presented as means $\pm \mathrm{SD}$

ND, plasma levels of DON and DON-3-GlcA were not detected or below LOQ

For example, maximum urinary level of DOM-1 following DON PO administration was $160 \pm 67 \mathrm{ng} / \mathrm{mL}$ in ruminating calves, while in non-ruminating calves only in one sample DOM-1 was detected $(1 \mathrm{ng} / \mathrm{mL})$. Urinary levels of
DOM-1 were still low following the first IV or PO bolus administration of DON in ruminating calves, however, an increased level was observed following the next PO administration (ruminating calf 1 : DON PO and ruminating calf 2: 15-ADON PO) (Fig. 5e). The period of urinary elimination of DOM-1 following consecutive single bolus administration of DON, 15-ADON, and 3-ADON was longer than the foreseen wash-out period of 4 days.

\section{Discussion}

In calves, feeding a low roughage to feed concentrate ratio, is characterized by an association between ruminal development and the systemic exposure to the mycotoxin DON. Although a higher solid feed provision will increase the animal's exposure to mycotoxins, non-optimal ruminal development caused by a shortage of roughage predisposes for DON intoxication in calves.

Intensive feeding regimes, which are used in the specialized modern veal and beef industry in order to maximize production efficiency, are associated with poor ruminal development. The limited amount of solid feed with a low roughage-to-feed concentrate ratio and the resulting insufficient structure in the diet limits natural rumination, which might lead to frustration, initiating stereotype behavior, such as tongue playing, cross-sucking, sucking on the feed trough and coat licking (Leruste et al. 2014; Mattiello et al. 2002; Webb et al. 2015). Therefore, a minimum daily uptake of solid feed of $250 \mathrm{~g}$ starting from the age of 8 weeks is compulsory (97/2/EC 1997), in order to improve animal welfare and gastro-intestinal health (Pardon et al. 2014; Webb et al. 2015). However, this small amount of solid feed does not guarantee complete ruminal development (Webb et al. 2015). Calves in specialized modern veal and beef industry are still fed intensively with milk replacer and cereals for 4-6 months, with only limited intake of roughage. Taking into account that all solid feed samples (roughage and concentrate feed) in this study were contaminated with at least one mycotoxin, and mycotoxin contamination of milk replacer was very low, the introduction of a minimal daily amount of solid feed increased the animal's exposure to mycotoxins.

Concentrate feed and roughage are both important sources of mycotoxins in the calf diet. In this study, all concentrate feed and roughage samples were contaminated with at least one mycotoxin. However, on average five different mycotoxins were detected. Co-occurrence of different mycotoxins in feed and feed raw materials can be explained by at least three reasons: most fungi are able to produce several mycotoxins concurrently, feed commodities can be contaminated by several fungi simultaneously or in quick succession, and animal diets are usually made up of multiple commodities (Smith et al. 2016). Roughage samples were mainly contaminated 
Fig. 3 Plasma concentration-time profile of 3-acetyldeoxynivalenol (3-ADON), deoxynivalenol (DON) and deoxynivalenol-3-glucuronide (DON-3-GlcA) after a intravenous (IV) and $\mathbf{b}$ oral (PO) administration of $25 \mu \mathrm{g}$ $3-\mathrm{ADON} / \mathrm{kg}$ bodyweight to two ruminating calves and two non-ruminating calves. Plasma levels of 3-ADON, DON, or DON-3-GlcA following PO 3-ADON administration were not detected or below LOQ in ruminating calves. Values are presented as means of $n=2+\mathrm{SD}$
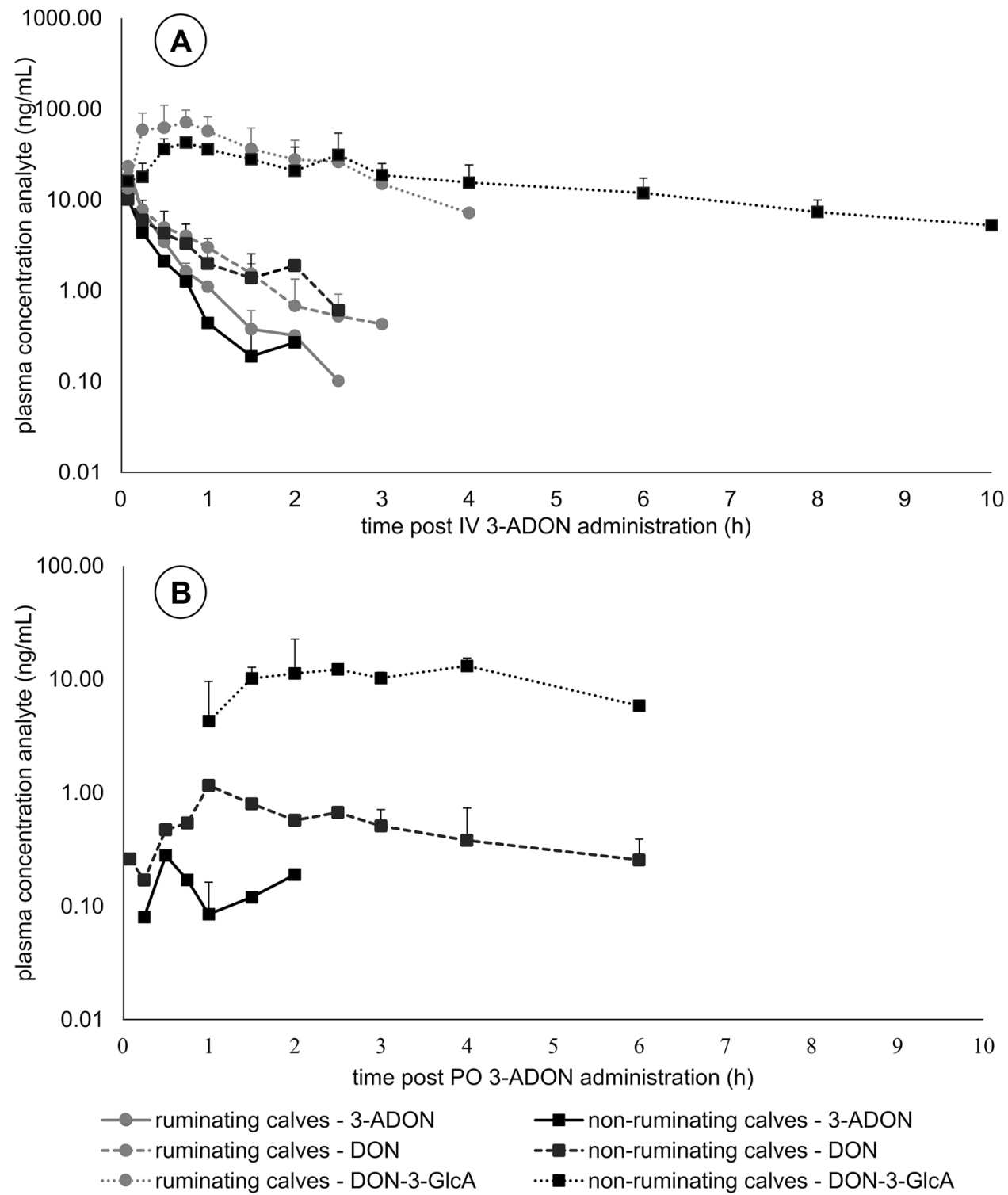

with DON, ADONs and enniatins. The maximum observed concentrations of these mycotoxins were higher in roughage than in concentrate feed. Recently, Ji et al. (2015) observed in case of Fusarium head blight the highest DON contamination levels in glumes, intermediate in straw, and the lowest in the grain. In contrast to other reports (Driehuis et al. 2008; Gallo et al. 2015), no zearalenone, fumonisins or aflatoxins were detected in the straw or maize silage samples in this study.

Roughage provision decreased the absolute oral bioavailability of DON by a factor 12 . The observed absolute oral bioavailability of $4.1 \%$ in ruminating calves is similar as described in sheep (5.9-9.9\%) (Prelusky et al. 1985). The higher oral bioavailability of $50.7 \%$ detected in nonruminating calves is similar as in pigs (54-100\%) (Broekaert et al. 2015b; Goyarts and Dänicke 2006), which is the most sensitive animal species for the toxic effects of DON, and results in a higher systemic exposure to the toxin. Furthermore, the lower $\mathrm{Vd}$ of DON and 3-ADON following IV administration in ruminating calves compared to nonruminating calves could be related to age-dependent differences in plasma protein concentration and binding capacity (Gasthuys et al. 2016). Feeding 5-week-old piglets a DONcontaminated diet $(1.5 \mathrm{mg} / \mathrm{kg}$ feed $)$ for 4 weeks induced disorganization of hepatic cords, cytoplasmatic vacuolization of hepatocytes and megalocytosis (Gerez et al. 2015). Accordingly, in the presented clinical case report a shortage of roughage induced liver failure in calves fed a mycotoxincontaminated diet.

Following IV administration a fraction of 3-ADON and $15-A D O N$ was hydrolysed to DON. However, the presence of ADONs in the urine demonstrates an incomplete systemic 
Fig. 4 Plasma concentrationtime profile of deoxynivalenol (DON) and deoxynivalenol3-glucuronide (DON-3-GlcA) after intravenous (IV) administration of $50 \mu \mathrm{g} 15-\mathrm{ADON} / \mathrm{kg}$ bodyweight to two ruminating calves and two non-ruminating calves. Values are presented as means of $n=2+\mathrm{SD}$. Plasma levels of 15-ADON above the LOQ were only measured in samples of 5 and 15 min postIV administration

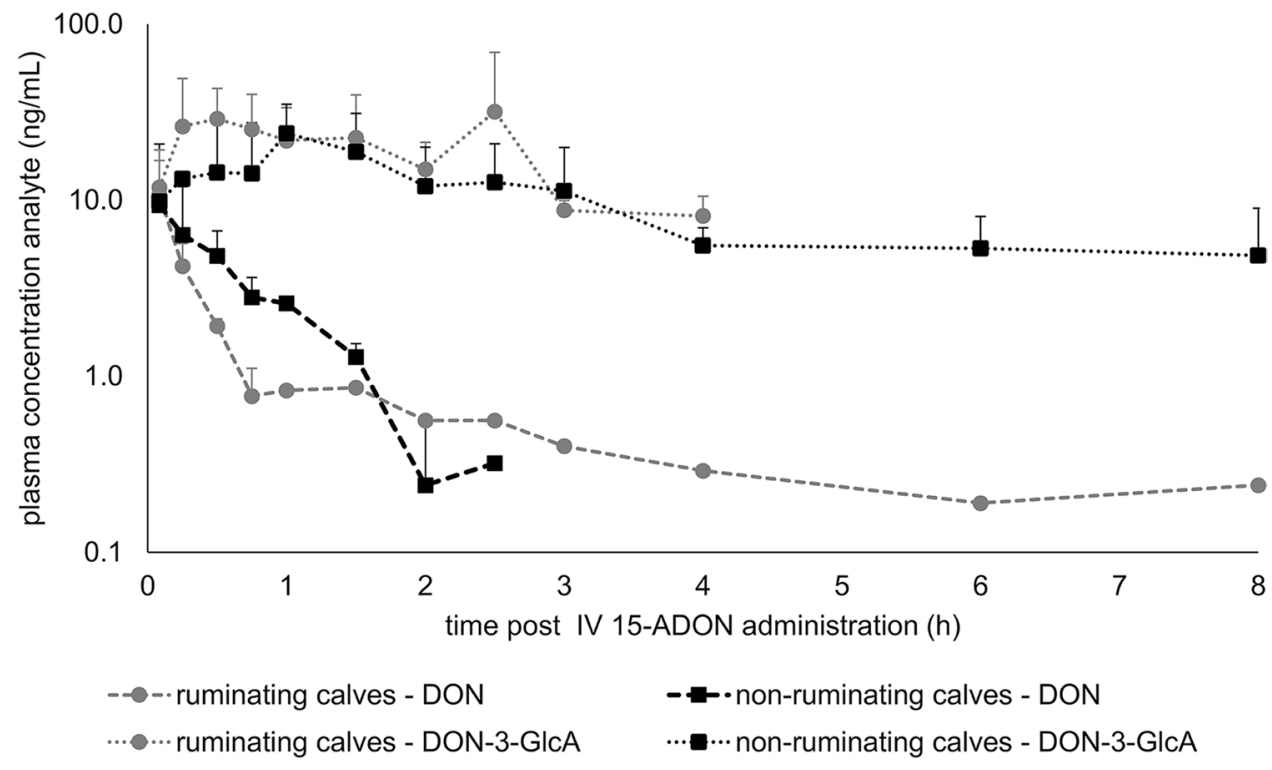

hydrolysis to DON. Besides, the ADONs can be hydrolyzed pre-systemically to DON by the intestinal microbiota (Broekaert et al. 2015b; Eriksen et al. 2003). Consequently, the absorbed fraction of ADONs following oral exposure may be characterized by a combination of absorption as DON and as ADON. Following PO administration of 3-ADON, only low plasma levels of DON were detected in non-ruminating calves. Taking into account the low number of animals in this study, and the very low oral absorption of 3-ADON in ruminating calves, a difference in the pre-systemic hydrolysis of 3-ADON and 15-ADON between ruminating and nonruminating calves could not be investigated. Further research should be performed using more calves and administering a higher oral dose of 3- and 15-ADON. The administered dosages of DON, 3-ADON, and 15-ADON in this study were based on the maximum contamination levels of the selected mycotoxins in the survey and the average daily feed intake. Taking into account the in vitro demonstrated toxicity of 3and 15-ADON on porcine epithelial cells (Broekaert et al. 2015b), and the hydrolysis of 3-ADON to the more toxic DON, toxicological importance of this acetylated form may not be underestimated.

The diagnosis of mycotoxicosis in clinical cases is mostly challenging. Liver failure is an uncommon clinical condition in calves, and can be associated with infectious diseases such as colibacillosis and salmonellosis, or intoxications such as heavy metal poisoning, seneciosis, and mycotoxins (Casteel et al. 1995; Craig et al. 1991; Ronzoni et al. 2013; Van Bost et al. 2001). In order to evaluate liver function in calves, it is very important to have established reference values for functional biomarkers. Traditionally, liver enzymes and liver function markers such as GLDH, GGT, AST, total biliary acids (TBA), and conjugated bilirubin, in combination with histology are used in diagnosing the cause of liver failure
(Smith and Magdesian 2009). In the presented clinical case report, a higher blood GGT level was observed in calves fed the Fusarium mycotoxin-contaminated diet. Definitive diagnosis should be based on the identification and quantification of the specific mycotoxin(s) in feed ingredients and finished feed. It is well known that so-called 'hot spots' in silages are responsible for an uneven distribution and non-proportional spread of mycotoxins in feed, highlighting the importance of representative sample collection and evaluation of mycotoxin exposure in animals. Recently, parent mycotoxins or their metabolites in biological samples such as plasma or urine have been proposed as biomarkers for exposure, and are indeed informative about the exposure of the animal on an individual level (Fruhmann et al. 2012; Warth et al. 2012; Winkler et al. 2014). A sensitive and specific UPLC-MS/ MS method was therefore developed to quantify DON and its metabolites in calf plasma and urine. DON and its acetylated forms were biotransformed by glucuronidation to DON-3-GlcA as major GlcA metabolite in plasma and urine. In contrast to Schwartz-Zimmermann et al. (2017), DON-15-GlcA was also demonstrated in the urine, although at low levels. Recently, Schwartz-Zimmermann et al. (2017) also described the presence of a minor metabolite iso-DON3-GlcA in cow urine; however, this metabolite was not included in this study.

In addition to hepatic glucuronidation, DON can also be metabolized by intestinal microbiota, with DOM-1 as most important microbial metabolite of DON (Fuchs et al. 2002). Microorganisms from rumen fluid could have both deacetylation and de-epoxidation functions, transforming ADONs to DON and DOM-1 (King et al. 1984). However, DOM-1 could not be detected in plasma in this study. Similarly, following a single IV $(0.5 \mathrm{mg} / \mathrm{kg})$ or PO $(5 \mathrm{mg} /$ $\mathrm{kg}$ ) administration of DON to sheep, only a minor portion 


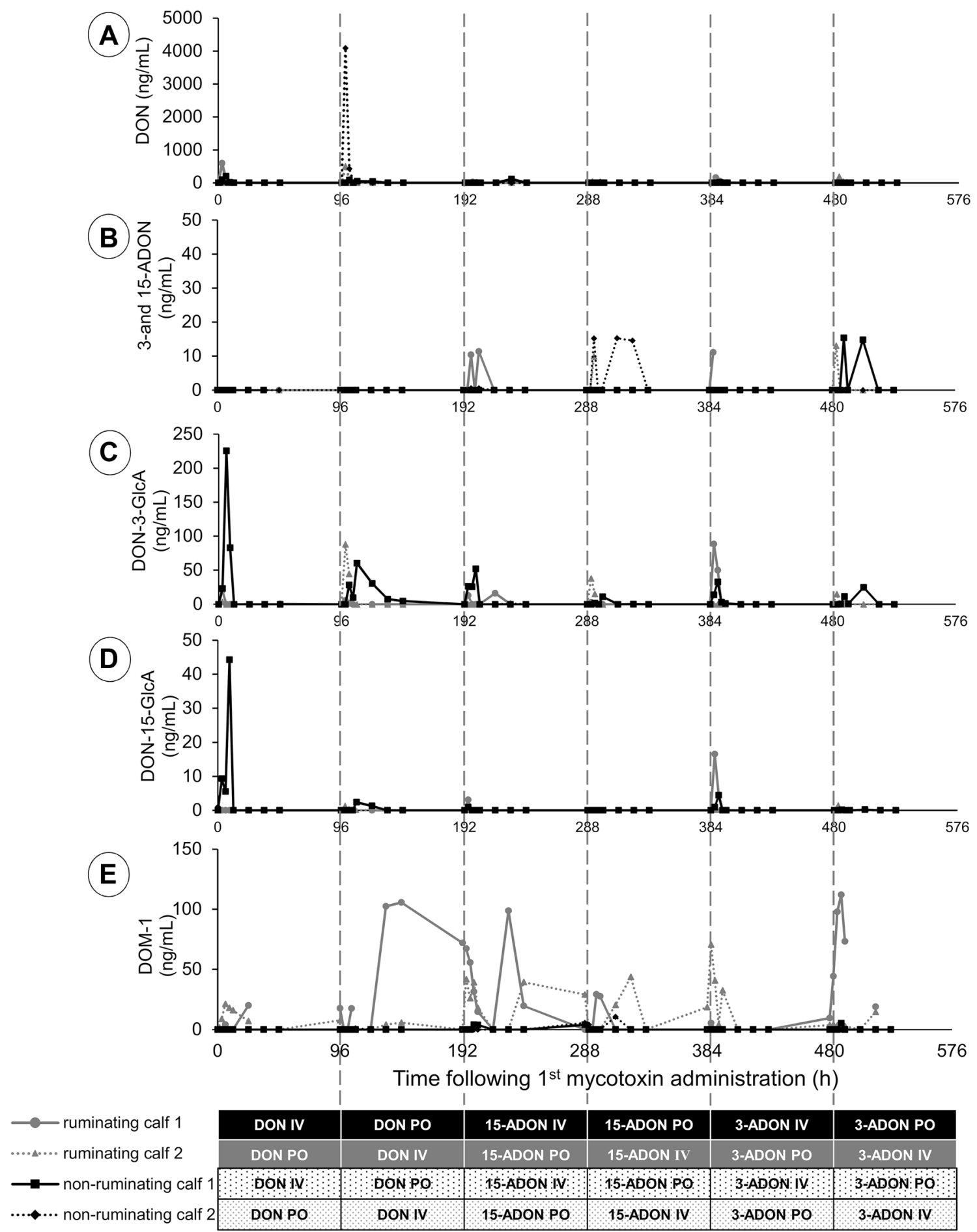

Fig. 5 Urine concentration-time profile of deoxynivalenol (DON), sum of acetylated derivatives (3- and 15-ADON), deoxynivalenol3-glucuronide (DON-3-GlcA), deoxynivalenol-15-glucuronide (DON-15-GlcA), and deepoxy-deoxynivalenol (DOM-1) after consecutive administration of a single bolus of DON $(120 \mu \mathrm{g} / \mathrm{kg} \mathrm{BW})$, 15-ADON $(50 \mu \mathrm{g} / \mathrm{kg} \mathrm{BW})$, and 3-ADON (25 $\mu \mathrm{g} / \mathrm{kg} \mathrm{BW})$ intravenously and orally to two ruminating calves and two non-ruminating calves in a cross-over design, with a 96-h wash-out period between each administration. For example, ruminating calf 1 was given first DON IV, $96 \mathrm{~h}$ later the animal was administered DON PO, and subsequently each time with $96 \mathrm{~h}$ interval, 15-ADON IV, 15-ADON PO, 3-ADON IV, and 3-ADON PO, respectively. Profiles are presented per individual animal 
(2.0\% and $0.3 \%$, respectively) of the dose was detected as DOM-1 in the plasma (Prelusky et al. 1985). In dairy cows fed a DON-contaminated diet for several weeks it was demonstrated that mainly DOM-1 was found in the proximal duodenum. Despite this high de-epoxidation degree, only $4-77 \%$ of DON-intake was recovered DON or DOM-1 in the duodenum (Dänicke et al. 2005; Seeling et al. 2006). This incomplete recovery of ingested DON at the duodenum suggests either absorption of DON and/or DOM-1 across the rumen epithelia and/or a complete degradation by rumen microbes. In this study it is suggested that roughage provision stimulate the intestinal microbial DON de-epoxidation capacity by the detection of only traces of DOM- 1 in the urine of non-ruminating calves while much higher levels were observed in ruminating calves following IV or PO administration of DON or its ADONs. In addition to DOM1, also GlcA metabolites of DOM-1 such as DOM-3-GlcA, iso-DOM-3-GlcA, and DOM-15-GlcA have been observed in cow urine samples (Schwartz-Zimmermann et al. 2017). Consequently, the low systemic DON bioavailability measured in sheep (Prelusky et al. 1985) and in ruminating calves in this study might be associated with significant total rumen degradation.

Taking into account the impact of roughage provision on the intestinal microbial de-epoxidation capacity, this study clearly indicates that plasma and urinary DOM-1 levels are not suited as biomarker in calves. The longer detection of DON-3-GlcA in plasma compared to DON, 3- and $15-\mathrm{ADON}$, might suggest the direct quantification of DON3-GlcA in calf plasma and/or urine as potential biomarker for exposure to DON. In humans, total urinary DON (sum of free DON and DON-GlcA) was validated as a biomarker of exposure with an average urinary excretion rate of $72 \%$ (Turner et al. 2010). Similarly, Van Limbergen et al. (2017) demonstrated that plasma DON-GlcA concentration is a good biomarker for DON exposure in sows.

In conclusion, a normal functioning rumen is capable of detoxifying DON, making ruminants less sensitive for these toxins (Dänicke et al. 2005). This was also demonstrated in this toxicokinetic study, where remarkable differences in the absolute oral bioavailability of DON were observed between ruminating and non-ruminating calves. However, in veal and beef calves on a low-fiber diet, rumen development is rudimentary, potentially making them more sensitive to mycotoxins. A multi-mycotoxin contamination of veal feed samples was demonstrated, especially in roughage and feed concentrate. DON was most prevalent, contaminating $80 \%$ of the roughage samples and all of the feed concentrate samples. Although, DON occurrence in calf feed will not affect food safety, mycotoxin contamination negatively affects animal health, demonstrated by a clinical case of liver failure on a beef farm. A clear link between ruminal development associated with roughage provision and the intestinal absorption of DON was demonstrated. Furthermore, calves are simultaneously exposed to DON and its acetylated forms. This study demonstrates that the latter are in vivo hydrolysed to DON. The European Union maximum guidance levels suggest that complete feed that does not exceed $2 \mathrm{mg}$ DON $/ \mathrm{kg}$ can be considered as safe for calves younger than 4 months of age, while $5 \mathrm{mg} / \mathrm{kg}$ applies for adult ruminants (2006/576/EC 2006). However, considering the above-mentioned results, also the acetylated forms should be taken into account. Furthermore, guidance levels should take into account the importance of ruminal development and solid feed provision, rather than only differentiate by age.

Acknowledgements The technical assistance of J. Muyle, F. Moons, C. Detavernier and E. Heyndrickx was gratefully appreciated. G. Antonissen was supported by a postdoctoral fellowships from Biomin Holding $\mathrm{GmbH}$ (Getzersdorf, Austria) and Research Foundation-Flanders $(12 \mathrm{~V} 6418 \mathrm{~N})$. The production of analytical standards of DON-3-GlcA and DON-sulfates was supported by B. Warth and funded by the Vienna Science and Technology Fund (WWTF LS12-021) and the Austrian Science fund (FWF, SFB Fusarium, F3702).

\section{Compliance with ethical standards}

Ethical approval All applicable international, national, and/or institutional guidelines for the care and use of animals were followed. All procedures performed in studies involving animals were in accordance with the ethical standards of the Ethical Committee of the Faculty of Veterinary Medicine and the Faculty of Bioscience Engineering of Ghent University (EC2014/93).

\section{References}

Antonissen G, Martel A, Pasmans F, Ducatelle R, Verbrugghe E, Vandenbroucke V, Li SJ, Haesebrouck F, Van Immerseel F, Croubels S (2014) The impact of Fusarium mycotoxins on human and animal host susceptibility to infectious diseases. Toxins 6:430-452

Antonissen G, Van Immerseel F, Pasmans F, Ducatelle R, Janssens GPJ, De Baere S, Mountzouris KC, Su S, Wong EA, De Meulenaer B, Verlinden M, Devreese M, Haesebrouck F, Novak B, Dohnal B, Martel A, Croubels S (2015) The mycotoxins deoxynivalenol and fumonisins alter the extrinsic component of intestinal barrier in broiler chickens. J Agric Food Chem 63:10846-10855

Bennett JW, Klich M (2003) Mycotoxins. Clin Microbiol Rev 16:497-516

Berends H, Van den Borne J, Mollenhorst H, Van Reenen C, Bokkers E, Gerrits W (2014) Utilization of roughages and concentrates relative to that of milk replacer increases strongly with age in veal calves. J Dairy Sci 97:6475-6484

Berthiller F, Crews C, Dall'Asta C, De Saeger S, Haesaert G, Karlovsky P, Oswald IP, Seefelder W, Speijers G, Stroka J (2013) Masked mycotoxins: a review. Mol Nutr Food Res 57:165-186

Bottalico A (1998) Fusarium diseases of cereals: species complex and related mycotoxin profiles, in Europe. J Plant Pathol 80:85-103

Bouhet S, Oswald IP (2005) The effects of mycotoxins, fungal food contaminants, on the intestinal epithelial cell-derived innate immune response. Vet Immunol Immunop 108:199-209

Bracarense APFL, Lucioli J, Grenier B, Pacheco GD, Moll W-D, Schatzmayr G, Oswald IP (2012) Chronic ingestion of 
deoxynivalenol and fumonisin, alone or in interaction, induces morphological and immunological changes in the intestine of piglets. Brit J Nutr 107:1776-1786

Broekaert N, Devreese M, De Baere S, De Backer P, Croubels S (2015a) Modified Fusarium mycotoxins unmasked: From occurrence in cereals to animal and human excretion. Food Chem Toxicol 80:17-31

Broekaert N, Devreese M, De Mil T, Fraeyman S, Antonissen G, De Baere S, De Backer P, Vermeulen A, Croubels S (2015b) Oral bioavailability, hydrolysis, and comparative toxicokinetics of 3-acetyldeoxynivalenol and 15-acetyldeoxynivalenol in broiler chickens and pigs. J Agric Food Chem 63:8734-8742

Broekaert N, Devreese M, van Bergen T, Schauvliege S, De Boevre M, De Saeger S, Vanhaecke L, Berthiller F, Michlmayr H, Malachová A, Adam G, Vermeulen A, Croubels S (2017) In vivo contribution of deoxynivalenol-3- $\beta$-D-glucoside to deoxynivalenol exposure in broiler chickens and pigs: oral bioavailability, hydrolysis and toxicokinetics. Arch Toxicol 91:699-712

Casteel S, Rottinghaus G, Johnson G, Wicklow D (1995) Liver disease in cattle induced by consumption of moldy hay. Vet Hum Toxicol 37:248-250

Craig AM, Pearson EG, Meyer C, Schmitz JA (1991) Serum liverenzyme and histopathologic changes in calves with chronic and chronic-delayed Senecio jacobaea toxicosis. Am J Vet Res 52:1969-1978

Dänicke S, Matthäus K, Lebzien P, Valenta H, Stemme K, Ueberschär K-H, Razzazi-Fazeli E, Böhm J, Flachowsky G (2005) Effects of Fusarium toxin-contaminated wheat grain on nutrient turnover, microbial protein synthesis and metabolism of deoxynivalenol and zearalenone in the rumen of dairy cows. J Anim Physiol Anim Nutr 89:303-315

De Boevre M, Di Mavungu JD, Landschoot S, Audenaert K, Eeckhout M, Maene P, Haesaert G, De Saeger S (2012) Natural occurrence of mycotoxins and their masked forms in food and feed products. World Mycotoxin J 5:207-219

Devreese M, Antonissen G, Broekaert N, De Mil T, De Baere S, Vanhaecke L, De Backer P, Croubels S (2015) Toxicokinetic study and oral bioavailability of DON in turkey poults, and comparative biotransformation between broilers and turkeys. World Mycotoxin J 8:533-539

Driehuis F, Spanjer MC, Scholten JM, Te Giffel MC (2008) Occurrence of mycotoxins in maize, grass and wheat silage for dairy cattle in the Netherlands. Food Addit Contam B 1:41-50

Eriksen GS, Pettersson H (2004) Toxicological evaluation of trichothecenes in animal feed. Anim Feed Sci Technol 114:205-239

Eriksen GS, Pettersson H, Lindberg JE (2003) Absorption, metabolism and excretion of 3-acetyl DON in pigs. Arch Tierernahr $57: 335-345$

European Commission (1997) 97/2/EC of 20 January 1997 amending Directive 91/629/EEC laying down minimum standards for the protection of calves. Off J Eur Commun L 025:24-25

European Commission (2002) 2002/657/EC implementing council directive 96/23/EC concerning the performances of analytical methods and the interpretation of results. Off $\mathrm{J}$ Eur Commun L 221:8-36

European Commission (2006) 2006/576/EC commission recommendation of 17 August 2006 on the presence of deoxynivalenol, zearalenone, ochratoxin A, T-2 and HT-2 and fumonisins in products intended for animal feeding. Off J Eur Union L229:7-9

Fink-Gremmels J (2008) Mycotoxins in cattle feeds and carry-over to dairy milk: a review. Food Addit Contam 25:172-180

Fruhmann P, Warth B, Hametner C, Berthiller F, Horkel E, Adam G, Sulyok M, Krska R, Fröhlich J (2012) Synthesis of deoxynivalenol-3-beta-D- $O$-glucuronide for its use as biomarker for dietary deoxynivalenol exposure. World Mycotoxin J 5:127-132
Fruhmann P, Skrinjar P, Weber J, Mikula H, Warth B, Sulyok M, Krska R, Adam G, Rosenberg E, Hametner C, Fröhlich J (2014) Sulfation of deoxynivalenol, its acetylated derivatives, and T2-toxin. Tetrahedron 70:5260-5266

Fuchs E, Binder E, Heidler D, Krska R (2002) Structural characterization of metabolites after the microbial degradation of type A trichothecenes by the bacterial strain BBSH 797. Food Addit Contam 19:379-386

Gallo A, Giuberti G, Frisvad JC, Bertuzzi T, Nielsen KF (2015) Review on mycotoxin issues in ruminants: occurrence in forages, effects of mycotoxin ingestion on health status and animal performance and practical strategies to counteract their negative effects. Toxins 7:3057-3111

Gasthuys E, Vandecasteele T, De Bruyne P, Vande Walle J, De Backer P, Cornillie P, Devreese M, Croubels S (2016) The potential use of piglets as human pediatric surrogate for preclinical pharmacokinetic and pharmacodynamic drug testing. Curr Pharm Des 22:4069-4085

Gerez JR, Pinton P, Callu P, Grosjean F, Oswald IP, Bracarense APFL (2015) Deoxynivalenol alone or in combination with nivalenol and zearalenone induce systemic histological changes in pigs. Exp Toxicol Pathol 67:89-98

Goyarts T, Dänicke S (2006) Bioavailability of the Fusarium toxin deoxynivalenol (DON) from naturally contaminated wheat for the pig. Toxicol Lett 163:171-182

Heitzman RJ (1994) Veterinary Drug Residues, Report Eur. 14126-EN. Commission of the EC, Brussels-Luxembourg

Ingalls J (1996) Influence of deoxynivalenol on feed consumption by dairy cows. Anim Feed Sci Technol 60:297-300

Ji F, Wu J, Zhao H, Xu J, Shi J (2015) Relationship of deoxynivalenol content in grain, chaff, and straw with Fusarium head blight severity in wheat varieties with various levels of resistance. Toxins 7:728-742

King RR, Mcqueen RE, Levesque D, Greenhalgh R (1984) Transformation of deoxynivalenol (vomitoxin) by rumen microorganisms. J Agric Food Chem 32:1181-1183

Knutsen HK, Alexander J, Barregård L, Bignami M, Brüschweiler B, Ceccatelli S, Cottrill B, Dinovi M, Grasl-Kraupp B, Hogstrand C, Hoogenboom L, Nebbia CS, Oswald IP, Petersen A, Rose M, Roudot A-C, Schwerdtle T, Vleminckx C, Vollmer G, Wallace H, De Saeger S, Eriksen GS, Farmer P, Fremy J-M, Gong YY, Meyer K, Naegeli H, Parent-Massin D, Rietjens I, van Egmond H, Altieri A, Eskola M, Gergelova P, Bordajandi LR, Benkova B, Dörr B, Gkrillas A, Gustavsson N, van Manen M, Edler L (2017) Risks to human and animal health related to the presence of deoxynivalenol and its acetylated and modified forms in food and feed. EFSA J. https://doi.org/10.2903/j.efsa.2017.4718

Königs M, Schwerdt G, Gekle M, Humpf HU (2008) Effects of the mycotoxin deoxynivalenol on human primary hepatocytes. Mol Nutr Food Res 52:830-839

Kovalsky P, Kos G, Nährer K, Schwab C, Jenkins T, Schatzmayr G, Sulyok M, Krska R (2016) Co-occurrence of regulated, masked and emerging mycotoxins and secondary metabolites in finished feed and maize - an extensive survey. Toxins 8:363

Leruste H, Brscic M, Cozzi G, Kemp B, Wolthuis-Fillerup M, Lensink BJ, Bokkers EAM, van Reenen CG (2014) Prevalence and potential influencing factors of non-nutritive oral behaviors of veal calves on commercial farms. J Dairy Sci 97:7021-7030

Maresca M (2013) From the gut to the brain: journey and pathophysiological effects of the food-associated trichothecene mycotoxin deoxynivalenol. Toxins 5(4):784-820

Mattiello S, Canali E, Ferrante V, Caniatti M, Gottardo F, Cozzi G, Andrighetto I, Verga M (2002) The provision of solid feeds to veal calves: II. Behavior, physiology, and abomasal damage. J Anim Sci 80:367-375 
Maul R, Warth B, Kant JS, Schebb NH, Krska R, Koch M, Sulyok M (2012) Investigation of the hepatic glucuronidation pattern of the Fusarium mycotoxin deoxynivalenol in various species. Chem Res Toxicol 25(12):2715-2717

Mikami O, Yamamoto S, Yamanaka N, Nakajima Y (2004) Porcine hepatocyte apoptosis and reduction of albumin secretion induced by deoxynivalenol. Toxicology 204:241-249

Monbaliu S, Van Poucke C, Detavernier C, Dumoulin F, Van De Velde M, Schoeters E, Van Dyck S, Averkieva O, Van Peteghem C, De Saeger S (2010) Occurrence of mycotoxins in feed as analyzed by a multi-mycotoxin LC-MS/MS method. J Agr Food Chem 58:66-71

Pardon B, Catry B, Boone R, Theys H, De Bleecker K, Dewulf J, Deprez $P$ (2014) Characteristics and challenges of the modern Belgian veal industry. Vlaams Diergen Tijds 83:155-163

Payros D, Alassane-Kpembi I, Pierron A, Loiseau N, Pinton P, Oswald IP (2016) Toxicology of deoxynivalenol and its acetylated and modified forms. Arch Toxicol 90:2931-2957

Pestka JJ, Smolinski AT (2005) Deoxynivalenol: toxicology and potential effects on humans. J Toxicol Environ Health B 8:39-69

Pinton P, Oswald IP (2014) Effect of deoxynivalenol and other type $B$ trichothecenes on the intestine: a review. Toxins 6:1615-1643

Prelusky DB, Veira DM, Trenholm HL (1985) Plasma pharmacokinetics of the mycotoxin deoxynivalenol following oral and intravenous administration to sheep. J Environ Sci Heal B 20:603-624

Prelusky DB, Hartin KE, Trenholm HL, Miller JD (1988) Pharmacokinetic fate of 14C-labeled deoxynivalenol in swine. Fundam Appl Toxicol 10:276-286

Ronzoni A, Bayrou C, Evrard L, Touati K, Sartelet A (2013) Hepatocholecystitis due to Salmonella Dublin in a crossbred calf. 1st Farah Day, Liège, Belgium (October 17, 2014)

Saint-Cyr MJ, Perrin-Guyomard A, Manceau J, Houée P, Delmas JM, Rolland JG, Laurentie M (2015) Risk assessment of deoxynivalenol by revisiting its bioavailability in pig and rat models to establish which is more suitable. Toxins 7:5167-5181

Schatzmayr G, Streit E (2013) Global occurrence of mycotoxins in the food and feed chain: facts and figures. World Mycotoxin J 6:213-222

Schwartz-Zimmermann HE, Hametner C, Nagl V, Slavik V, Moll WD, Berthiller F (2014) Deoxynivalenol (DON) sulfonates as major DON metabolites in rats: from identification to biomarker method development, validation and application. Anal Bioanal Chem 406:7911-7924

Schwartz-Zimmermann HE, Fruhmann P, Dänicke S, Wiesenberger G, Caha S, Weber J, Berthiller F (2015) Metabolism of deoxynivalenol and deepoxy-deoxynivalenol in broiler chickens, pullets, roosters and turkeys. Toxins 7:4706-4729

Schwartz-Zimmermann HE, Hametner C, Nagl V, Fiby I, Macheiner L, Winkler J, Dänicke S, Clark E, Pestka JJ, Berthiller F (2017) Glucuronidation of deoxynivalenol (DON) by different animal species: identification of iso-DON glucuronides and iso-deepoxyDON glucuronides as novel DON metabolites in pigs, rats, mice, and cows. Arch Toxicol 91:3857-3872

Seeling K, Dänicke S, Valenta H, van Egmond HP, Schothorst RC, Jekel AA, Lebzien P, Schollenberger M, Razzazi-Fazeli E, Flachowsky G (2006) Effects of Fusarium toxin-contaminated wheat and feed intake level of the biotransformation and carry-over of deoxynivalenol in dairy cows. Food Addit Contam 23:1008-1020
Smith BP, Magdesian KG (2009) Alterations in alimentary and hepatic function. In: Smith BP (ed) Large animal internal medicine, 4th edn. Mosby Elsevier, Davis, pp 96-116

Smith MC, Madec S, Coton E, Hymery N (2016) Natural co-occurrence of mycotoxins in foods and feeds and their in vitro combined toxicological effects. Toxins 8:94

Thompson WL, Wannemacher RW (1986) Structure-function-relationships of 12,13-epoxytrichothecene mycotoxins in cell-culture comparison to whole animal lethality. Toxicon 24:985-994

Thompson M, Ellison SL, Wood R (2002) Harmonized guidelines for single-laboratory validation of methods of analysis (IUPAC Technical Report). Pure Appl Chem 74:835-855

Turner PC, White KL, Burley VJ, Hopton RP, Rajendram A, Fisher J, Cade JE, Wild CP (2010) A comparison of deoxynivalenol intake and urinary deoxynivalenol in UK adults. Biomarkers 15:553-562

Van Bost S, Roels S, Mainil J (2001) Necrotoxigenic Escherichia coli type-2 invade and cause diarrhoea during experimental infection in colostrum-restricted newborn calves. Vet Microbiol 8:315-329

Van Asselt ED, Azambuja W, Moretti A, Kastelein P, De Rijk TC, Stratakou I, Van Der Fels-Klerx HJ (2012) A Dutch field survey on fungal infection and mycotoxin concentrations in maize. Food Addit Contam Part A 29:1556-1565

Van Limbergen T, Devreese M, Croubels S, Broekaert N, Michiels A, De Saeger S, Maes D (2017) Role of mycotoxins in herds with and without problems with tail necrosis in neonatal pigs. Vet Rec 181:539

VICH GL 49 (2011) Studies to evaluate the metabolism and residue kinetics of veterinary drugs in food producing animals: validation of analytical methods used in residue depletion studies. http:// www.fda.gov/downloads/AnimalVeterinary/GuidanceComplia nceEnforcement/GuidanceforIndustry/UCM207942.pdf. Accessed 1 Mar 2015

Wan D, Huang L, Pan Y, Wu Q, Chen D, Tao Y, Wang X, Liu Z, Li J, Wang L, Yuan Z (2014) Metabolism, distribution, and excretion of deoxynivalenol with combined techniques of radiotracing, high-performance liquid chromatography ion trap time-of-flight mass spectrometry, and online radiometric detection. J Agric Food Chem 62:288-296

Warth B, Sulyok M, Fruhmann P, Berthiller F, Schuhmacher R, Hametner C, Adam G, Fröhlich J, Krska R (2012) Assessment of human deoxynivalenol exposure using an LC-MS/MS based biomarker method. Toxicol Lett 211:85-90

Webb LE, van Reenen C, Berends H, Engel B, de Boer IJM, Gerrits WJJ, Bokkers EAM (2015) The role of solid feed amount and composition and of milk replacer supply in veal calf welfare. J Dairy Sci 98:5467-5481

Winkler J, Kersten S, Valenta H, Hüther L, Meyer U, Engelhardt U, Dänicke S (2014) Simultaneous determination of zearalenone, deoxynivalenol and their metabolites in bovine urine as biomarkers of exposure. World Mycotoxin J 8:63-74

Yoshizawa T, Cote LM, Swanson SP, Buck WB (1986) Confirmation of DOM-1, a de-epoxidation metabolite of deoxynivalenol, in biological-fluids of lactating cows. Agric Biol Chem 50:227-222

Zhang J, Shi H, Wang Y, Li S, Zhang H, Cao Z, Yang K (2018) Effects of limit-feeding diets with different forage-to-concentrate ratios on nutrient intake, rumination, ruminal fermentation, digestibility, blood parameters and growth in Holstein heifers. Anim Sci J 89:527-536 


\section{Affiliations}

Bonnie Valgaeren ${ }^{1,2} \cdot$ Léonard Théron $^{3} \cdot$ Siska Croubels $^{4} \cdot$ Mathias Devreese $^{4} \cdot$ Siegrid De Baere $^{4}$.

Els Van Pamel ${ }^{5}$. Els Daeseleire ${ }^{5}$. Marthe De Boevre ${ }^{6}$. Sarah De Saeger ${ }^{6} \cdot$ Arnau Vidal $^{6}$. José Diana Di Mavungu ${ }^{6}$. Philipp Fruhmann ${ }^{7,8}$. Gerhard Adam ${ }^{8}$. Alfons Callebaut ${ }^{9} \cdot$ Calixte Bayrou $^{10}$. Vincent Frisée ${ }^{3}$. Anne-Sophie Rao ${ }^{3}$. Emilie Knapp $^{3} \cdot$ Arnaud Sartelet $^{3} \cdot$ Bart Pardon $^{1} \cdot$ Piet Deprez $^{1} \cdot$ Gunther Antonissen ${ }^{4,11}$ (])

1 Department of Large Animal Internal Medicine, Faculty of Veterinary Medicine, Ghent University, Merelbeke, Belgium

2 Faculty of Science and Technology, University College Ghent, Melle, Belgium

3 Clinical Department of Production Animals, Faculty of Veterinary Medicine, University of Liège, Liège, Belgium

4 Department of Pharmacology, Toxicology and Biochemistry, Faculty of Veterinary Medicine, Ghent University, Merelbeke, Belgium

5 Flanders Research Institute for Agriculture, Fisheries and Food (ILVO), Technology and Food Science Unit-Food Safety, Melle, Belgium

6 Department of Bioanalysis, Faculty of Pharmaceutical Sciences, Ghent University, Ghent, Belgium
Institute of Applied Synthetic Chemistry, Vienna University of Technology, Vienna, Austria

8 Department of Applied Genetics and Cell Biology, University of Natural Resources and Life Sciences, Tulln, Austria

9 Veterinary and Agrochemical Research Centre, CODA-CERVA, Tervuren, Belgium

10 Department of Pathology, Faculty of Veterinary Medicine, University of Liège, Liège, Belgium

11 Department of Pathology, Bacteriology and Avian Diseases, Faculty of Veterinary Medicine, Ghent University, Merelbeke, Belgium 